\title{
A New Family of Continuous Distributions: Properties, Copulas and Real Life Data Modeling
}

\author{
Mohamed K. A. Refaie* \\ Agami High Institute of Administrative Sciences, Alexandria, Egypt
}

\begin{abstract}
A new family of distributions called the Kumaraswamy Rayleigh family is defied and studied. Some of its relevant statistical properties are derived. Many new bivariate type $G$ families using the of Farlie-Gumbel-Morgenstern, modified Farlie-Gumbel-Morgenstern copula, Clayton copula and Renyi's entropy copula are derived. The method of the maximum likelihood estimation is used. Some special models based on log-logistic, exponential, Weibull, Rayleigh, Pareto type II and Burr type X, Lindley distributions are presented and studied. Three dimensional skewness and kurtosis plots are presented. A graphical assessment is performed. Two real life applications to illustrate the flexibility, potentiality and importance of the new family is proposed.
\end{abstract}

Keywords Kumaraswamy Family, Rayleigh family, Clayton Copula Farlie Gumbel, Morgenstern Family, Simulation; Modeling.

AMS 2010 subject classifications 60E05, 62G05, 62N05, 62P30

DOI:10.19139/soic-2310-5070-1130

\section{Introduction and motivation}

Recently, there has been an exceptional eagerness for growing more flexible families of distributions by extending the classical cumulative distribution functions (CDFs). Many generalized families of distributions have been defied and studied for modeling different lifetime data in many applied areas such as insurance, engineering, economics, environmental sciences, medical sciences, biological studies and finance. So, several G classes of continuous probability distributions have been constructed by expanding the common families of distributions. These generalized distributions give more flexibility by to the baseline family. The well-known continuous probability distributions such as Weibull, Burr type X, gamma, normal, beta, Burr XII, beta, Kumaraswamy, LogLogistic, Topp-Leone and Lindley are widely used because of theirs simple forms. Recently, many statisticians have focused on the more complex and flexible continuous probability distributions for increasing the applicable ability of these well-known models via adding one or more shape parameters. The well-known family of distributions can be cited as follows: Marshall and Olkin [42] (Marshall and Olkin family), Zografos and Balakrishnan [63] (gamma family), Cordeiro and de Castro [13] (Kumaraswamy family), Yousof et al. [57] (Burr type X family), Cordeiro et al.[12] (Burr type XII family), Merovci et al.[43] (exponentiated transmuted family), Aryal and Yousof [8] (exponentiated generalized-G Poisson family), Brito et al. [10] (Topp-Leone odd log-logistic family), Korkmaz et al. [33] (generalized odd Weibull generated family), Korkmaz et al. [35] (exponential Lindley odd log-logistic family), Korkmaz et al. [36] (Marshall-Olkin generalized-G Poisson family), Nascimento et al. [46] (Nadarajah-Haghighi family), Merovci et al. [44] (Poisson Topp Leone family), Karamikabir et al. [32] (Weibull

\footnotetext{
*Correspondence to: Mohamed K. A. Refaie(E-mail: refaie_top@yahoo.com).
}

ISSN 2310-5070 (online) ISSN 2311-004X (print)

Copyright (C) 2021 International Academic Press 
Topp-Leone generated family), Korkmaz et al. [34] (Hjorth family), Alizadeh et al. [4] (flexible Weibull generated family), Alizadeh et al. [5] (transmuted odd log-logistic family) and El-Morshedy et al. [16] (Poisson generalized exponential family)

Consider a baseline $\operatorname{CDF} G_{\underline{\Psi}}(z)$ with parameter vector $\underline{\boldsymbol{\Psi}}$ where $\underline{\boldsymbol{\Psi}}=\left(\underline{\boldsymbol{\Psi}}_{k}\right)=\left(\boldsymbol{\Psi}_{1}, \boldsymbol{\Psi}_{2}, \ldots\right)$. Then due to Yousof et al. [57], the survival function (SF) of the R-G family of distributions is defined as

$$
\overline{\mathbf{H}}_{\sigma, \underline{\underline{\Psi}}}(z)=1-\mathbf{H}_{\sigma, \underline{\boldsymbol{\Psi}}}(z)=\left.\exp \left[-\frac{1}{\sigma} \omega_{\underline{\mathbf{\Psi}}}^{2}(z)\right]\right|_{\sigma>0, z \in \mathbb{R}}
$$

where

$$
\omega_{\underline{\Psi}}^{2}(z)=\frac{1}{\left[G_{\underline{\underline{\Psi}}}^{-1}(z)-1\right]^{2}}
$$

and $\bar{G}_{\underline{\Psi}}(z)=1-G_{\underline{\Psi}}(z)$ is the SF of the baseline model. In this paper, we define and study a new family of distributions by adding two extra shape parameters to (1) to provide more flexibility to the new generated family. Using the Kumaraswamy-G (K-G) family (Cordeiro and de Castro [13]), we construct a new family called the Kumaraswamy Rayleigh-G (KR-G) family. For an arbitrary baseline CDF $\mathbf{H}_{\sigma, \underline{\underline{\Psi}}}(z)$, the K-G family by the CDF given by $F_{\underline{\mathbf{V}}}(z)=1-\left.\left[1-\mathbf{H}_{\sigma, \underline{\mathbf{\Psi}}}^{\zeta}(z)\right]^{\gamma}\right|_{(\underline{\mathbf{V}}=\zeta, \gamma, \sigma, \underline{\mathbf{\Psi}})}$. Following Cordeiro and de Castro [13], the SF of the KR-G family can be expressed as

$$
\bar{F}_{\underline{\mathbf{V}}}(z)=1-F_{\zeta, \gamma, \underline{\Psi}}(z)=\left.\left(1-h_{z ;, \zeta, \sigma, \underline{\underline{\Psi}}}\right)^{\gamma}\right|_{\sigma, \zeta, \gamma \in \mathbb{R}^{+}} \text {and } z \in \mathbb{R},
$$

where

$$
h_{z ;, \zeta, \sigma, \underline{\Psi}}=\left\{1-\exp \left[-\frac{1}{\sigma} \omega_{\sigma, \underline{\Psi}}^{2}(z)\right]\right\}^{\zeta} .
$$

The probability density function (PDF) corresponding to (2) can be derived as

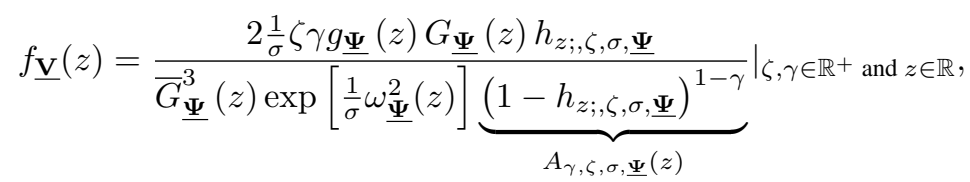

where $g_{\underline{\Psi}}(z)$ refer to the baseline PDF with parameter vector $\underline{\boldsymbol{\Psi}}$. We are motivated to define and study the KR-G family for the following reasons:

1. The PDF of the KR-G family can be "symmetric", "heavy tailed right skewed" and "right skewed" with many useful shapes. The failure rate of the KR-G family can be "increasing", "bathtub", "J-shape", "decreasing", "decreasing-constant", "increasing-constant" and "constant" .

2. In modeling real-life data, the new family proved its superiority against the special generalized mixture-G family, odd log-logistic-G family, Burr-Hatke-G family transmuted Topp-Leone-G family, gamma-G family, Kumaraswamy-G family, beta-G family and Exponentiated-G family.

3. In modeling the bimodal real-life, the new family provides better fits in modeling the bimodal right skewed and bimodal right skewed data sets.

The rest of the paper is outlined as follows. In Section 2, some general mathematical properties of the proposed KR-G family are derived. In Section 3, Simple type copula using Farlie Gumbel Morgenstern (FGM) copula, modified FGM copula, Clayton copula and Renyi's entropy are presented. Maximum likelihood estimation of the model parameters is investigated in Section 4. Nine special models of this family are presented in Section 5 corresponding to the baseline Log-Logistic, Exponential, Weibull, Rayleigh, Pareto type-II and Burr X, Lindley 
distributions. Section 6 provides a graphical simulation study for testing the performance of the maximum likelihood method in estimating the parameters of the Kumaraswamy Rayleigh Pareto type-II model as a special case. Section 7 provides two applications to real data sets to illustrate the potentiality of the new KR-G family and the Kumaraswamy Rayleigh Pareto type-II is compared with the special generalized mixture Pareto type-II, Odd log-logistic Pareto type-II, Reduced Odd log-logistic Pareto type-II, Reduced Burr-Hatke Pareto type-II, Transmuted Topp-Leone Pareto type-II, Reduced Transmuted Topp-Leone Pareto type-II, Gamma Pareto type-II, Kumaraswamy Pareto type-II, Beta Pareto type-II, Exponentiated Pareto type-II, standard Pareto type-II and Proportional reversed hazard rate Pareto type-II models. Finally, some concluding remarks are presented in Section 8.

\section{Statistical properties}

\subsection{Useful expansions}

Consider the following series

$$
\begin{gathered}
\left(1-\frac{\pi_{1}}{\pi_{2}}\right)^{\pi_{3}}=\left.\sum_{j_{1}=0}^{\infty} \frac{(-1)^{j_{1}} \Gamma\left(1+\pi_{3}\right)}{j_{1} ! \Gamma\left(1+\pi_{3}-j_{1}\right)}\left(\frac{\pi_{1}}{\pi_{2}}\right)^{j_{1}}\right|_{\pi_{3}>0 \text { and }\left|\frac{\pi_{1}}{\pi_{2}}\right|<1}, \\
\exp \left(-\frac{\pi_{1}}{\pi_{2}}\right)=\sum_{\kappa_{1}=0}^{\infty} \frac{(-1)^{\kappa_{1}}}{\Gamma\left(1+\kappa_{1}\right)}\left(\frac{\pi_{1}}{\pi_{2}}\right)^{\kappa_{1}},
\end{gathered}
$$

and

$$
\left(1-\frac{\pi_{1}}{\pi_{2}}\right)^{-\pi_{3}}=\left.\sum_{\kappa_{2}=0}^{\infty} \frac{\Gamma\left(\pi_{3}+\kappa_{2}\right)}{\kappa_{2} ! \Gamma\left(\pi_{3}\right)}\left(\frac{\pi_{1}}{\pi_{2}}\right)^{\kappa_{2}}\right|_{\pi_{3}>0,\left|\frac{\pi_{1}}{\pi_{2}}\right|<1}
$$

Applying (4) to $A_{\gamma, \zeta, \sigma, \underline{\Psi}}(z)$, equation (3) reduces to

$$
f_{\underline{\mathbf{V}}}(z)=\frac{2 \zeta \gamma g_{\underline{\mathbf{\Psi}}}(z) G_{\underline{\Psi}}(z)}{\bar{G}_{\underline{\mathbf{\Psi}}}^{3}(z) \exp \left[\frac{1}{\sigma} \omega_{\underline{\mathbf{\Psi}}}^{2}(z)\right]} \sum_{j_{1}=0}^{\infty} \frac{(-1)^{j_{1}} \Gamma(\gamma)}{j_{1} ! \Gamma\left(\gamma-j_{1}\right)} \underbrace{\left[1-\exp \left[-\frac{1}{\sigma} \omega_{\underline{\mathbf{\Psi}}}^{2}(z)\right]\right]^{\zeta\left(1+j_{1}\right)-1}}_{B_{j_{1}, \zeta, \sigma, \underline{\Psi}}(z)} .
$$

By expanding $B_{j_{1}, \zeta, \sigma, \underline{\Psi}}(z)$ again using (4), equation (7) becoms

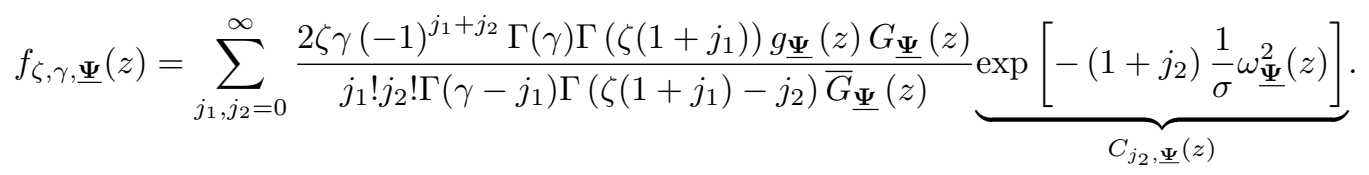

Applying (5) to $C_{j_{2}, \underline{\Psi}}(z)$ where

$$
C_{j_{2}, \underline{\Psi}}(z)=\exp \left[-\left(1+j_{2}\right) \frac{1}{\sigma} \omega_{\underline{\Psi}}^{2}(z)\right]
$$

we get

$$
\begin{aligned}
f_{\underline{\mathbf{V}}}(z)= & \sum_{j_{1}, \kappa_{1}, j_{2}=0}^{\infty} \frac{(-1)^{j_{1}+j_{2}+\kappa_{1}}\left(j_{2}+1\right)^{\kappa_{1}} \Gamma(\gamma) \Gamma\left(\zeta\left(1+j_{1}\right)\right)}{j_{1} ! j_{2} ! \kappa_{1} ! \Gamma\left(\gamma-j_{1}\right) \Gamma\left(\zeta\left(1+j_{1}\right)-j_{2}\right)} \\
& \times 2 \zeta \gamma g_{\underline{\Psi}}(z) G_{\underline{\Psi}}(z)^{2 \kappa_{1}+1} \underbrace{\bar{G}_{\underline{\Psi}}(z)^{-2 \kappa_{1}-3}}_{D_{\kappa_{1}, \underline{\Psi}}(z)} 10
\end{aligned}
$$


Finally expanding $D_{\kappa_{1}, \underline{\Psi}}(z)$ using (6), equation (7) can be expressed as

$$
f_{\underline{\mathbf{V}}}(z)=\left.\sum_{\kappa_{1}, \kappa_{2}=0}^{\infty} \mathbf{C}_{\kappa_{1}, \kappa_{2}} \pi_{\kappa} \cdot(z)\right|_{\kappa} \cdot=2 \kappa_{1}+\kappa_{2}+2,
$$

where $\pi_{\kappa} \bullet(z)=\kappa^{\bullet} g_{\underline{\Psi}}(z) G_{\underline{\Psi}}(z)^{\kappa^{\bullet}-1}$ denotes the PDF of the exponentiated G (ExG) densities with power parameter $\kappa^{\bullet}$ and

$$
\mathbf{C}_{\kappa_{1}, \kappa_{2}}=2 \zeta \gamma \frac{1}{\sigma} \sum_{j_{1}, j_{2}=0}^{\infty} \frac{(-1)^{j_{1}+j_{2}+\kappa_{1}}\left(j_{2}+1\right)^{\kappa_{1}} \Gamma(\gamma) \Gamma\left(\zeta\left(1+j_{1}\right)\right) \Gamma\left(2 \kappa_{1}+3+\kappa_{2}\right)}{j_{1} ! j_{2} ! \kappa_{1} ! \kappa_{2} ! \Gamma\left(\gamma-j_{1}\right) \Gamma\left(\zeta\left(1+j_{1}\right)-j_{2}\right) \Gamma\left(2 \kappa_{1}+3\right) \kappa^{\bullet}} .
$$

Similarly, the CDF of the KR-G family can be expressed as

$$
F_{\underline{\mathbf{V}}}(z)=\sum_{\kappa_{1}, \kappa_{2}=0}^{\infty} \mathbf{C}_{\kappa_{1}, \kappa_{2}} \Pi_{\kappa} \cdot(s l z),
$$

where $\Pi_{\kappa} \bullet(z)=G_{\underline{\Psi}}(z)^{\kappa^{\bullet}}$ denotes the PDF of the exponentiated G (ExG) densities with power parameter $\kappa^{\bullet}$. Henceforward, we will consider the scale parameter $\sigma=1$ for obtaining more simple family with less number of parameters.

\subsection{Quantile function}

Quantile functions are used in theoretical aspects, statistical applications and Monte Carlo methods. Monte-Carlo simulations employ quantile functions to produce simulated random variables for classical and new continuous distributions. The KR quantile function, say $z=Q(u)$ can be obtained by inverting (2), we have

$$
F^{-1}(u)=Q_{G}(u)=\left.G^{-1}\left[-\frac{1}{2} q_{u^{*}, \gamma, \zeta} /\left(1-\frac{1}{2} q_{u^{*}, \gamma, \zeta}\right)\right]\right|_{\left(u^{*}=1-u\right)},
$$

where $q_{u^{*}, \gamma, \zeta}=\log \left[1-\left(1-u^{* \frac{1}{\gamma}}\right)^{\frac{1}{\zeta}}\right]$. We can easily generate $z$ by taking $u$ as a uniform random variable in $(0,1)$.

\subsection{Moments}

Let $Z_{\kappa^{\bullet}}$ be a random variable having the ExG with density $\left.\pi_{\kappa^{\bullet}}(z)\right|_{\kappa^{\bullet}=2 \kappa_{1}+\kappa_{2}+2}$ an dpower parameter $\kappa^{\bullet}$. The $\mathrm{r}^{\text {th }}$ moment of KR-G family can be obtained from (11) as

$$
\mu_{r, Z}^{\prime}=\mathbb{E}\left(Z^{r}\right)=\sum_{\kappa_{1}, \kappa_{2}=0}^{\infty} \mathbf{C}_{\kappa_{1}, \kappa_{2}} \mathbb{E}\left(Z_{\kappa}^{r} \bullet\right)
$$

and

$$
\mathbb{E}\left(Z_{\kappa}^{r}\right)=\left.\kappa_{-\infty}^{\bullet}{ }^{\infty} z^{r} g_{\underline{\Psi}}(z) G_{\underline{\Psi}}(z)^{\kappa^{\bullet}-1}\right|_{\kappa}>0
$$

where $\mathbb{E}\left(Z_{\kappa}^{r}\right)$ can be calculated numerically in terms of the baseline quantile function, i.e., $Q_{G}(u)=G^{-1}(u)$ as $\mathbb{E}\left(Z_{\kappa}^{r}\right)=\kappa_{0}^{\bullet 1} u^{\kappa^{\bullet}-1} Q_{G}(u)^{r} d u$.

\subsection{Incomplete momemts}

The $\mathrm{s}^{\text {th }}$ incomplete moment of $Z$ is given by

$$
m_{s, Z}(y)=\int_{-\infty}^{t} z^{s} f(z) d z .
$$


Using (11), the $\mathrm{s}^{\text {th }}$ incomplete moment of KR-G family is $m_{s, Z}(t)=\sum_{\kappa_{1}, \kappa_{2}=0}^{\infty} \mathbf{C}_{\kappa_{1}, \kappa_{2}} m_{s, \kappa} \bullet(y)$ where $m_{s, \kappa} \bullet(t)=$ $\int_{0}^{G(t)} Q_{G}^{s}(u) u^{\kappa^{\bullet}-1} d u$. The $m_{s, \kappa} \bullet(t)$ can be calculated numerically by using the software such as Matlab, R, Mathematica etc.

\subsection{Moment generating function}

Now we introduce two formulae for the moment generating function. The first formula

$$
M_{Z}(t)=\mathbb{E}\left(\mathbb{E}^{t z}\right)=\sum_{\kappa_{1}, \kappa_{2}=0}^{\infty} \mathbf{C}_{\kappa_{1}, \kappa_{2}} M_{\kappa} \cdot(t)
$$

where $M_{\kappa} \bullet(t)$ is the moment generating function of $Z_{\kappa}$. Consequently, we can be easily determined $M_{Z}(t)$ from the ExG generating function. The secone formula

$$
M_{Z}(t)=\mathbb{E}\left(e^{t z}\right)=\sum_{\kappa_{1}, \kappa_{2}=0}^{\infty} \mathbf{C}_{\kappa_{1}, \kappa_{2}} M_{\kappa} \cdot(t)
$$

where $M_{\kappa} \bullet(t)$ is the mgf of random variable $Z_{\kappa} \bullet$ given by

$$
\left.M_{\kappa} \cdot(t)\right|_{\kappa^{\bullet}>0}=\kappa_{-\infty}^{\bullet} \exp (t z) g_{\underline{\Psi}}(z) G_{\underline{\Psi}}(z)^{\kappa^{\bullet}-1}=\kappa_{0}^{\bullet 1} u^{\kappa^{\bullet}-1} \exp \left[t Q_{G}(u)\right] d u
$$

which can be calculated numerically from the baseline quantile function, i.e., $Q_{G}(u)=G^{-1}(u)$. For the KRPTII model

$$
M_{Z}(t)=\left.\sum_{\kappa_{1}, \kappa_{2}, r=0}^{\infty} \sum_{\kappa_{3}=0}^{r} \frac{t^{r}}{r !} \mathbf{C}_{\kappa_{1}, \kappa_{2}, \kappa_{3}}^{\left(\kappa^{\bullet}, r\right)} \mathcal{B}\left(\kappa, \frac{\kappa_{3}-r}{b}+1\right)\right|_{b>r}
$$

\section{Copulas}

We derive some new bivariate type KR (Biv-KR) model using FGM copula, modified FGM copula, Clayton copula and Renyi's entropy. The Multivariate KR (MvKR) type is also presented. However, future works may be allocated to study these new models.

\subsection{Biv-KR type via FGM copula}

Consider the joint CDF of the FGM family $\delta(u, w)=u w\left(1+\delta u^{*} w^{*}\right)$, where the marginal function $u=F_{1}$, $w=F_{2}, \delta \in(-1,1)$ is a dependence parameter and for every $u, w \in(0,1),(u, 0)=(0, w)=0$ which is "grounded minimum" and $(u, 1)=u$ and $(1, w)=w$ which is "grounded maximum", $\left(u_{1}, w_{1}\right)+\left(u_{2}, w_{2}\right)-\left(u_{1}, w_{2}\right)-$ $\left(u_{2}, w_{1}\right) \geq 0$ (see Gumbel [27] and Gumbel [28]). A copula is continuous in $u$ and $w$; actually, it satisfies the stronger Lipschitz condition, where

$$
\left|\left(u_{2}, w_{2}\right)-\left(u_{1}, w_{1}\right)\right| \leq\left|u_{2}-u_{1}\right|+\left|w_{2}-w_{1}\right| .
$$

For $0 \leq u_{1} \leq u_{2} \leq 1$ and $0 \leq w_{1} \leq w_{2} \leq 1$, we have

$$
\operatorname{Pr}\left(u_{1} \leq U \leq u_{2}, w_{1} \leq W \leq w_{2}\right)=\left(u_{1}, w_{1}\right)+\left(u_{2}, w_{2}\right)-\left(u_{1}, w_{2}\right)-\left(u_{2}, w_{1}\right) \geq 0 .
$$

Then, setting $u^{*}=\left.\left(1-h_{z_{1} ; \zeta_{1}, \underline{\Psi}}\right)^{\gamma_{1}}\right|_{u \in[0,1]}$ and $w^{*}=\left.\left(1-h_{z_{2} ; \zeta_{2}, \underline{\Psi}}\right)^{\gamma_{2}}\right|_{w \in[0,1]}$, we get

$$
\begin{aligned}
\left(F_{1}, F_{2}\right)= & F\left(z_{1}, z_{2}\right)=\left[1-\left(1-h_{z_{1} ; \zeta_{1}, \underline{\Psi}}\right)^{\gamma_{1}}\right]\left[1-\left(1-h_{z_{2} ; \zeta_{2}, \underline{\Psi}}\right)^{\gamma_{2}}\right] \\
& \times\left\{1+\delta\left[\left(1-h_{z_{1} ; \zeta_{1}, \underline{\Psi}}\right)^{\gamma_{1}}\left(1-h_{z_{2} ; \zeta_{2}, \underline{\Psi}}\right)^{\gamma_{2}}\right]\right\} .
\end{aligned}
$$


The joint PDF can then derived from

$$
\wp_{\delta}(u, w)=1+\left.\delta u^{*} w^{*}\right|_{\left(u^{*}=1-2 u \text { and } w^{*}=1-2 w\right)}
$$

or from

$$
f\left(z_{1}, z_{2}\right)=\wp\left(F_{1}, F_{2}\right) f_{1} f_{2} .
$$

\subsection{BvOBGR type via modified FGM copula}

Due to Rodriguez-Lallena and Ubeda-Flores [52]), the modified version of the bivariate FGM copula is defined as

$$
{ }_{\delta}(u, w)=\left.u w[1+\delta \vartheta(u) \omega(w)]\right|_{\delta \in(-1,1)}
$$

or

$$
{ }_{\delta}(u, w)=u w+\left.\delta \dot{\vartheta}_{u} \dot{\omega}_{w}\right|_{\delta \in(-1,1)}
$$

where $\dot{\vartheta}_{u}=u \vartheta(u)$, and $\dot{\omega}_{w}=w \omega(w)$. Where

$$
\vartheta(u=0)=\vartheta(u=1)=\omega(w=0)=\omega(w=1)=0 .
$$

Let

$$
\begin{gathered}
\tau_{1}=\inf \left\{\dot{\vartheta}_{u}:\left.\frac{\partial}{\partial u} \dot{\vartheta}_{u}\right|_{\epsilon_{1}}\right\}<0, \tau_{2}=\sup \left\{\dot{\vartheta}_{u}:\left.\frac{\partial}{\partial u} \dot{\vartheta}_{u}\right|_{\epsilon_{1}}\right\}<0, \\
\xi_{1}=\inf \left\{\dot{\omega}_{w}:\left.\frac{\partial}{\partial w} \dot{\omega}_{w}\right|_{\epsilon_{2}}\right\}>0, \xi_{2}=\sup \left\{\dot{\omega}_{w}:\left.\frac{\partial}{\partial w} \dot{\omega}_{w}\right|_{\epsilon_{2}}\right\}>0,
\end{gathered}
$$

Then,

$$
1 \leq \min \left(\tau_{1} \tau_{2}, \xi_{1} \xi_{2}\right)<\infty
$$

where

$$
\begin{gathered}
u \frac{\partial}{\partial u} \vartheta(u)=\frac{\partial}{\partial u} \dot{\vartheta}_{u}-\vartheta(u), \\
\epsilon_{1}=\left\{u:\left.u \in(0,1)\right|_{\frac{\partial}{\partial u} \dot{\vartheta}_{u}} \text { exists }\right\},
\end{gathered}
$$

and

$$
\epsilon_{2}=\left\{w: w \in(0,1) \mid \frac{\partial}{\partial w} \dot{\omega}_{w} \text { exists }\right\} .
$$

3.2.1. Biv-KR-FGM (Type-I) model Here, we consider the following functional form for both $\vartheta(u)$ and $\omega(w)$. Then considering $\delta(u, w)=u w+\left.\delta \dot{\vartheta}_{u} \dot{\omega}_{w}\right|_{\delta \in(-1,1)}$, we get

$$
{ }_{\delta}(u, w)=\delta \dot{\vartheta}_{u} \dot{\omega}_{w}+\left\{\left[1-\left(1-h_{u ; \zeta_{1}, \underline{\Psi}}\right)^{\gamma_{1}}\right]\left[1-\left(1-h_{w ; \zeta_{2}, \underline{\Psi}}\right)^{\gamma_{2}}\right]\right\},
$$

where $\dot{\vartheta}_{u}=u\left(1-\left\{1-\exp \left[-\omega_{\underline{\Psi}}(u)\right]\right\}^{\zeta_{1}}\right)^{\gamma_{1}}$ and $\dot{\omega}_{w}=w\left(1-\left\{1-\exp \left[-\omega_{\underline{\Psi}}(w)\right]\right\}^{\zeta_{2}}\right)^{\gamma_{2}}$.

3.2.2. Biv-KR-FGM (Type-II) model Let $\vartheta(u)$ and $\omega(w)$ be two functional form for satisfy all the conditions stated earlier where

$$
\left.\vartheta(u)^{*}\right|_{\left(\delta_{1}>0\right)}=u^{\delta_{1}}(1-u)^{1-\delta_{1}} \text { and }\left.\omega(w)^{*}\right|_{\left(\delta_{2}>0\right)}=w^{\delta_{2}}(1-w)^{1-\delta_{2}} .
$$

The corresponding Biv-KR-FGM (Type-II) can be derived from

$$
\delta, \delta_{1}, \delta_{2}(u, w)=u w\left[1+\delta \vartheta(u)^{*} \omega(w)^{*}\right] .
$$


3.2.3. Biv-KR-FGM (Type-III) model Let $\ddot{\vartheta}(u)=u\left[\log \left(1+u^{*}\right)\right]$ and $\ddot{w}(w)=w\left[\log \left(1+w^{*}\right)\right]$ for all $\vartheta(u)$ and $\omega(w)$ which satisfies all the conditions stated earlier. In this case, one can also derive a closed form expression for the associated CDF of the Biv-KR-FGM (Type-III) from $\Upsilon(u, w)=u w(1+\delta \ddot{\vartheta}(u) \ddot{\omega}(w))$.

3.2.4. Biv-KR-FGM (Type-IV) model According to Ghosh and Ray [26] the CDF of the Biv-KR-FGM (Type-IV) model can be derived from

$$
{ }_{\delta}(u, w)=u F^{-1}(w)+w F^{-1}(u)-F^{-1}(u) F^{-1}(w)
$$

Then,

$$
F^{-1}(u)=G^{-1}\left(\frac{-\frac{1}{2} c_{u^{*}, \zeta_{1}, \gamma_{1}}}{1-\frac{1}{2} c_{u^{*}, \zeta_{1}, \gamma_{1}}}\right), F^{-1}(w)=G^{-1}\left(\frac{-\frac{1}{2} c_{v^{*}, \zeta_{2}, \gamma_{2}}}{1-\frac{1}{2} c_{v^{*}, \zeta_{2}, \gamma_{2}}}\right)
$$

where

$$
c_{u^{*}, \zeta_{1}, \gamma_{1}}=\log \left[1-\sqrt[\zeta_{1}]{1-\sqrt[\gamma_{1}]{u^{*}}}\right]
$$

and

$$
c_{v^{*}, \zeta_{2}, \gamma_{2}}=\log \left[1-\sqrt[\zeta_{2}]{1-\sqrt[\gamma_{2}]{v^{*}}}\right]
$$

\subsection{Biv-KR type via Clayton copula}

The Clayton copula can be considered as

$$
\left(w_{1}, w_{2}\right)=\left.\left[\left(1 / w_{1}\right)^{\Upsilon}+\left(1 / w_{2}\right)^{\Upsilon}-1\right]^{-\frac{1}{\Upsilon}}\right|_{\Upsilon \in[0, \infty]} .
$$

Let us assume that $T \sim \mathrm{KR}\left(\zeta_{1}, \gamma_{1}, \underline{\Psi}\right)$ and $Z \sim \mathrm{KR}\left(\zeta_{2}, \gamma_{2}, \underline{\Psi}\right)$. Then, setting

$$
w_{1}=w(t)=\left[1-\left(1-h_{t ; \zeta_{1}, \underline{\Psi}}\right)^{\gamma_{1}}\right]
$$

and

$$
w_{2}=w(z)=\left[1-\left(1-h_{z ; \zeta_{1}, \underline{\Psi}}\right)^{\gamma_{2}}\right],
$$

Then, the Biv-KR type distribution can be derived as

$$
(t, z)=(F(t), F(z))=\left[\begin{array}{c}
\left(\left[1-\left(1-h_{t ; \zeta_{1}, \underline{\Psi}}\right)^{\gamma_{1}}\right]\right)^{-\Upsilon} \\
+\left(\left[1-\left(1-h_{z ; \zeta_{1}, \underline{\Psi}}\right)^{\gamma_{2}}\right]\right)^{-\Upsilon}-1
\end{array}\right]^{-\frac{1}{\Upsilon}} .
$$

\subsection{Biv-KR type via Renyi's entropy copula}

Consider theorem of Pougaza and Djafari [47] where

$$
R(u, w)=z_{2} u+z_{1} w-z_{1} z_{2} .
$$

Then, the associated Biv-KR will be

$$
\begin{aligned}
R\left(z_{1}, z_{2}\right)= & R\left(F\left(z_{1}\right), F\left(z_{2}\right)\right)=-z_{1} z_{2} \\
& +z_{2}\left[1-\left(1-h_{z_{1} ; \zeta_{1}, \underline{\Psi}}\right)^{\gamma_{1}}\right] \\
& +z_{1}\left[1-\left(1-h_{z_{2} ; \zeta_{2}, \underline{\Psi}}\right)^{\gamma_{2}}\right] .
\end{aligned}
$$




\subsection{MvKR extention via Clayton copula}

The MvKR ( $m$-dimensional extension) from the above can be derived from $\left(w_{i}\right)=\left[\sum_{i=1}^{m} w_{i}^{-\Upsilon}+1-m\right]^{-\frac{1}{\Upsilon}}$. Then, the MvKR extention can expressed as

$$
(\underline{Z})=\left(\sum_{i=1}^{m}\left\{\left[1-\left(1-h_{z_{i} ; \zeta_{i}, \underline{\Psi}}\right)^{\gamma_{i}}\right]\right\}^{-\Upsilon}+1-m\right)^{-\frac{1}{\Upsilon}},
$$

where $\underline{Z}=z_{1}, z_{2}, \cdots, z_{m}$.

\section{Maximum likelihood estimation}

The MLEs enjoy desirable properties and can be used when constructing confidence intervals and regions and also in test statistics. We determine the maximum likelihood estimates (MLEs) of the parameters of the KR-G family of distributions from complete samples only. Let $z_{1}, z_{2}, \ldots, z_{n}$ be a random sample of size $n$ from the KR-G family. The $\log$-likelihood function for $\underline{\mathbf{V}}$ is given by

$$
\begin{aligned}
L_{n}(\underline{\mathbf{V}})= & n \log (2 \zeta \gamma)+\sum_{i=0}^{n} \log g_{\underline{\mathbf{\Psi}}}\left(z_{i}\right)+\sum_{i=0}^{n} \log G_{\underline{\underline{\Psi}}}\left(z_{i}\right) \\
& +(\zeta-1) \sum_{i=0}^{n} \log \left\{1-\exp \left[-\omega_{\underline{\mathbf{\Psi}}}^{2}\left(z_{i}\right)\right]\right\}-\sum_{i=0}^{n} \omega_{\underline{\mathbf{\Psi}}}^{2}\left(z_{i}\right) \\
& +(\gamma-1) \sum_{i=0}^{n} \log \left(1-h_{z_{i} ; \zeta, \underline{\underline{\Psi}}}\right)-3 \sum_{i=0}^{n} \log \bar{G}_{\underline{\boldsymbol{\Psi}}}\left(z_{i}\right) .
\end{aligned}
$$

The components of the score function $\mathbf{U}_{n}(\underline{\mathbf{V}})=\left(\mathbf{U}_{n}(\zeta), \mathbf{U}_{n}(\gamma), \mathbf{U}_{n}(\underline{\mathbf{\Psi}})\right)$. Setting the nonlinear system of equations $\mathbf{U}_{n}(\zeta), \mathbf{U}_{n}(\gamma), \mathbf{U}_{n}(\underline{\boldsymbol{\Psi}})$ equal to zero and solving the equations simultaneously yields the maximum likelihood estimation (MLE) of $\underline{\mathbf{V}}$, say $\underline{\mathbf{V}}$, where these equations cannot be solved analytically, so, we use any statistical software to solve these equations.

\section{Special models}

This section presents some special KR models based on Log-Logistic (LL), Exponential (E), Weibull (W), Rayleigh (R), Pareto type-II (PTII) and Burr X (BrX), Lindley (Li) distributions. Table 1 below presents some new submodels based on the new KR-G family. Figure 1 gives PDF and HRF plots of the Kumaraswamy Rayleigh Weibull (KRW) model. Figure 2 gives PDF and HRF plots of the Kumaraswamy Rayleigh Pareto type-II (KRPTII) model. Based on Figure 1 (right panel), the PDF of the KRPTII can be "symmetric" and "right skewed" with many useful shapes. Based on Figure 1 (left panel), the HRF of the KRPTII can be increasing", "bathtub", " J-shape", "decreasing", "decreasing-constant" and "increasing-constant". Based on Figure 1 (right panel), the PDF of the KRPTII can be "symmetric" and "heavy tailed right skewed" with many useful shapes. Based on Figure 2 (left panel), the HRF of the KRPTII can be "increasing", "bathtub", "decreasing", "constant" and "J-shape". Figure 3 and 5 gives the three dimensional skewness plots for KRW and KRPTII models respectively. Figure 4 and 6 provides the three dimensional kurtosis plots for KRW and KRPTII models respectively.

For the KRPTII model, we have

$$
\mu_{r, Z}^{\prime}=\left.\sum_{\kappa_{1}, \kappa_{2}=0}^{\infty} \sum_{\kappa_{3}=0}^{r} \mathbf{C}_{\kappa_{1}, \kappa_{2}, \kappa_{3}}^{\left(\kappa^{\bullet}, r\right)} \mathcal{B}\left(\kappa^{\bullet}, \frac{\kappa_{3}-r}{b}+1\right)\right|_{b>r},
$$



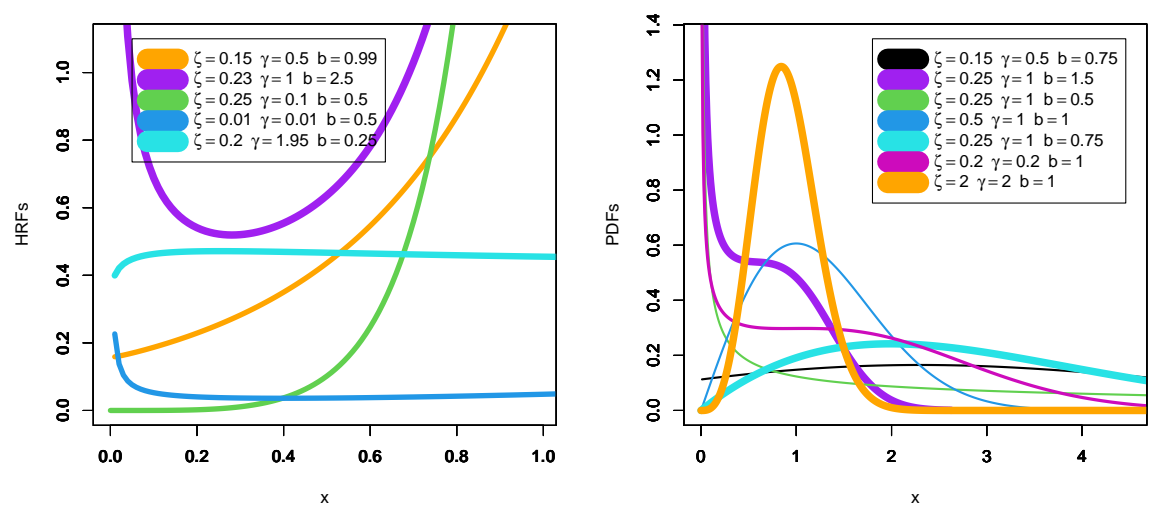

Figure 1. PDF plots and HRF plots of the KRW model.

and

$$
m_{s, Z}(t)=\left.\sum_{\kappa_{1}, \kappa_{2}=0}^{\infty} \sum_{\kappa_{3}=0}^{s} \mathbf{C}_{\kappa_{1}, \kappa_{2}, \kappa_{3}}^{\left(\kappa^{\bullet}, s\right)} \mathcal{B}_{t}\left(\kappa^{\bullet}, \frac{\kappa_{3}-s}{b}+1\right)\right|_{b>r},
$$

where

$$
\begin{array}{r}
\mathbf{C}_{\kappa_{1}, \kappa_{2}, \kappa_{3}}^{\left(\kappa^{\bullet}, r\right)}=\mathbf{C}_{\kappa_{1}, \kappa_{2}} \kappa^{\bullet}(-1)^{\kappa_{3}}\left(\begin{array}{c}
r \\
\kappa_{3}
\end{array}\right), \\
\mathcal{B}\left(w_{1}, w_{2}\right)={ }_{0}^{1} t^{w_{1}-1}(1-t)^{w_{2}-1} d t
\end{array}
$$

is the complete beta function and

$$
\mathcal{B}_{y}\left(w_{1}, w_{2}\right)={ }_{0}^{y} t^{w_{1}-1}(1-t)^{w_{2}-1} d t
$$

is the incomplete beta function.

Table 1. New submodels based on the new KR-G family.

\begin{tabular}{ccccc}
\hline No. & Baseline model & The new model & $\omega_{\boldsymbol{\Psi}}^{2}(z)$ & Suport \\
\hline \hline 1 & LL & KRLL & $\left(\frac{1}{\alpha} z\right)^{2 b}$ & $\zeta, \gamma, \alpha, b \in \mathbb{R}^{+}$ \\
2 & E & KRE & {$[\exp (a z)-1]^{2}$} & $\zeta, \gamma, a \in \mathbb{R}^{+}$ \\
3 & W & KRW & $\left\{\exp \left[(a z)^{b}\right]-1\right\}^{2}$ & $\zeta, \gamma, a, b \in \mathbb{R}^{+}$ \\
4 & W & KRW & {$\left[\exp \left(z^{b}\right)^{-1}\right]^{2}$} & $\zeta, \gamma, b \in \mathbb{R}^{+}$ \\
5 & R & KRR & $\left\{\exp \left[(a z)^{2}\right]-1\right\}^{2}$ & $\zeta, \gamma, a \in \mathbb{R}^{+}$ \\
6 & R & KRR & {$\left[\exp \left(z^{2}\right)^{-}-1\right]^{2}$} & $\zeta, \gamma \in \mathbb{R}^{+}$ \\
7 & PTII & KRPTII & {$\left[(1+z)^{b}-1\right]^{2}$} & $\zeta, \gamma, b \in \mathbb{R}^{+}$ \\
8 & BrX & KRBrX & $\left(\left\{1-\exp \left[-(a z)^{2}\right]\right\}^{-b}-1\right)^{-2}$ & $\zeta, \gamma, a, b \in \mathbb{R}^{+}$ \\
9 & Li & KRLi & {$\left[\left(\frac{1+a+a z}{1+a}\right)^{-1} \exp (a z)-1\right]^{2}$} & $\zeta, \gamma, a \in \mathbb{R}^{+}$ \\
\hline \hline
\end{tabular}



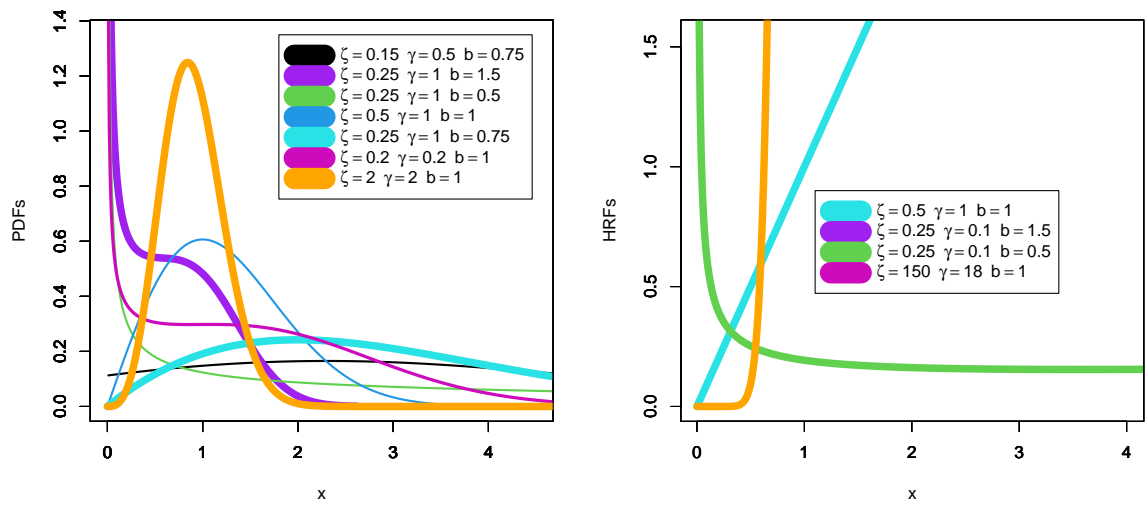

Figure 2. PDF plots and HRF plots of the KRPTII model.
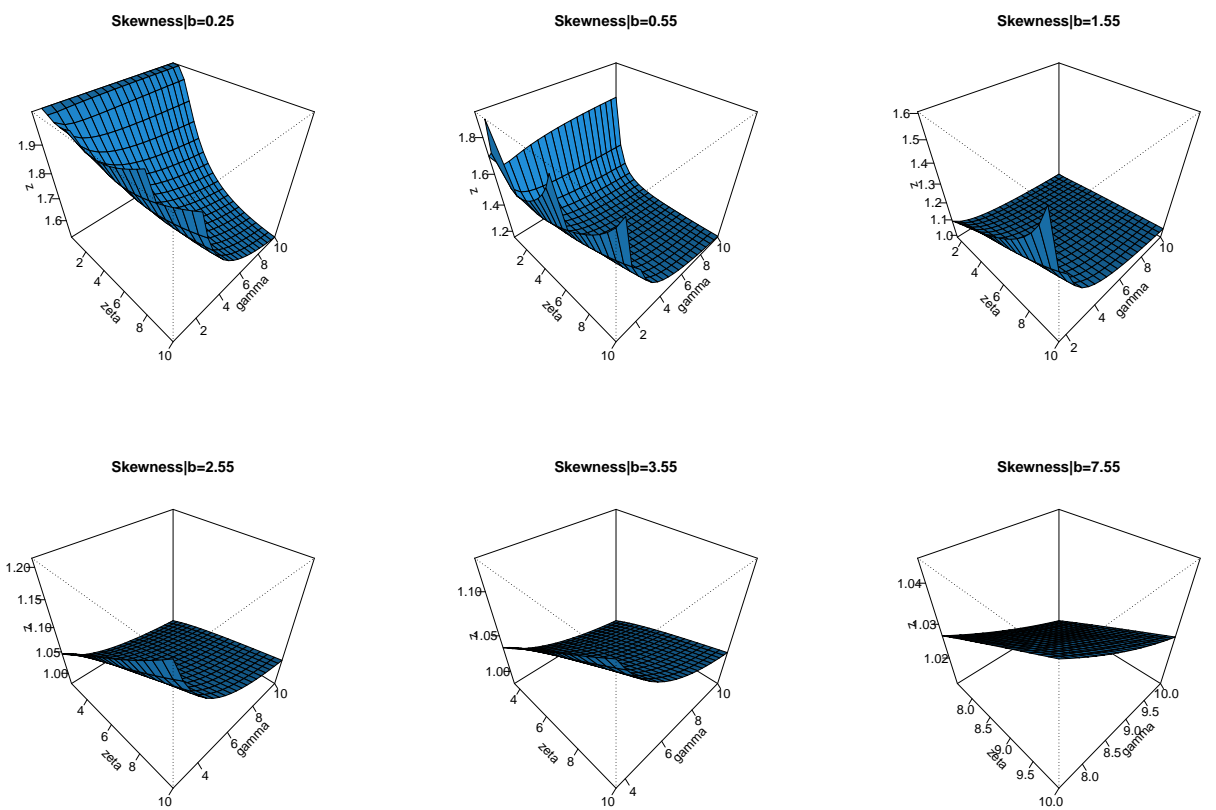

Figure 3. Three dimensional skewness plots (KRW model).

\section{Simulations}

To assess of the finite sample behavior of the MLEs, we will consider and apply the following algorithm:

1. Use

$$
z_{u}=\left[\left(-\ln \left\{1-\left[1-(1-u)^{\frac{1}{\gamma}}\right]^{\frac{1}{\zeta}}\right\}\right)^{\frac{1}{2}}+1\right]^{\frac{1}{b}}-1
$$



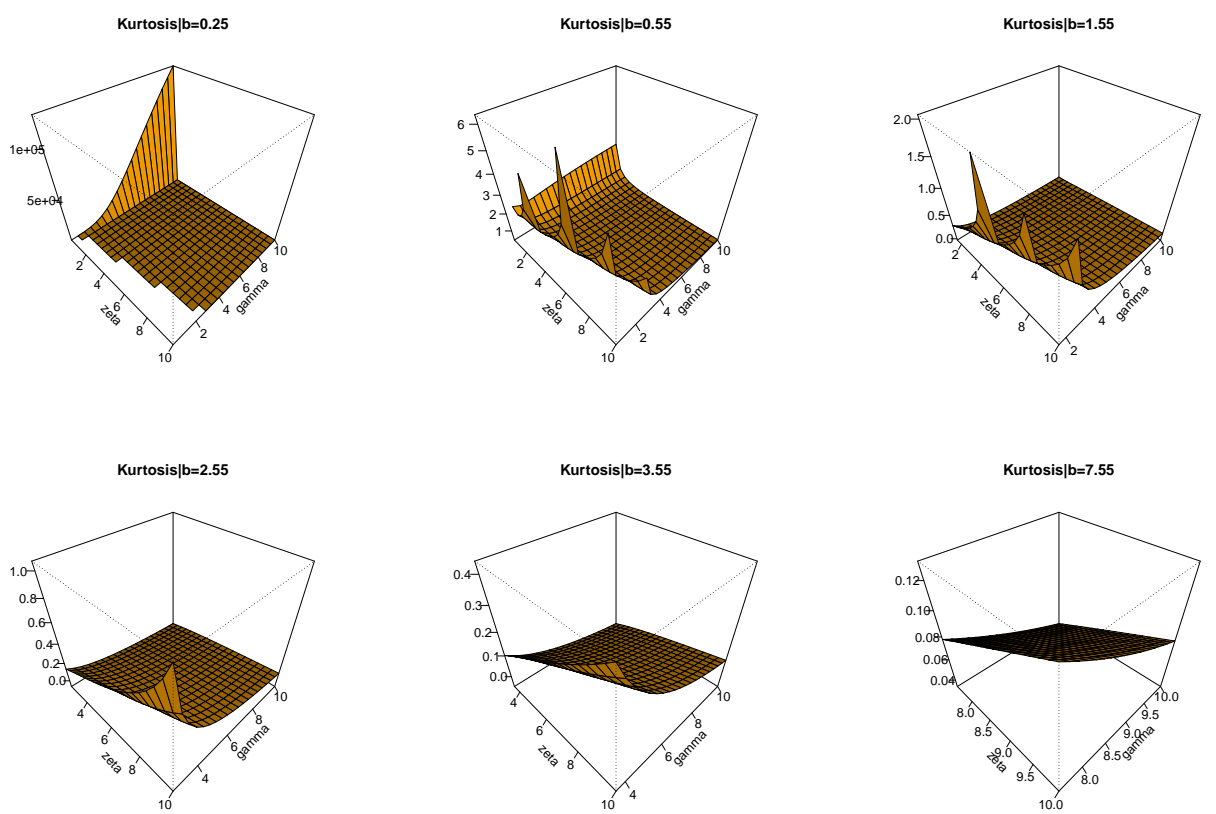

Figure 4. Three dimensional kurtosis plots (KRW model).
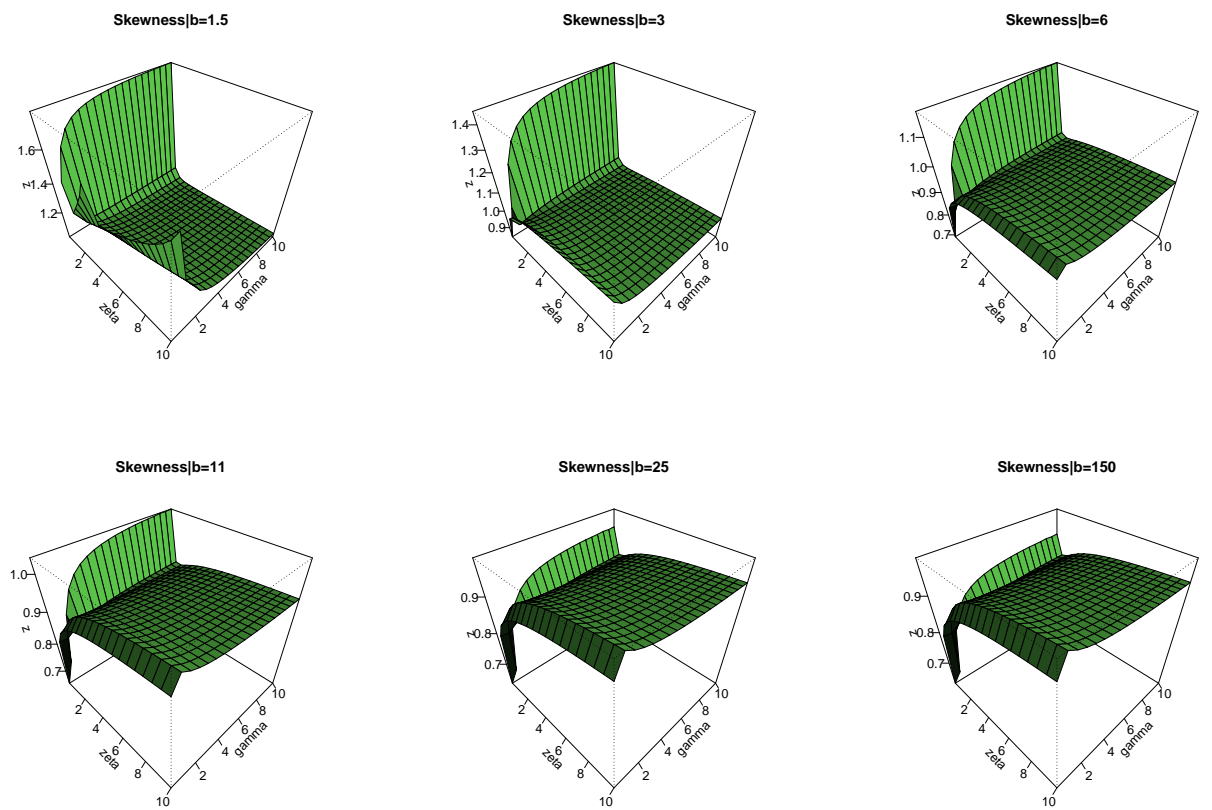

Figure 5. Three dimensional skewness plots (KRPTII model). 

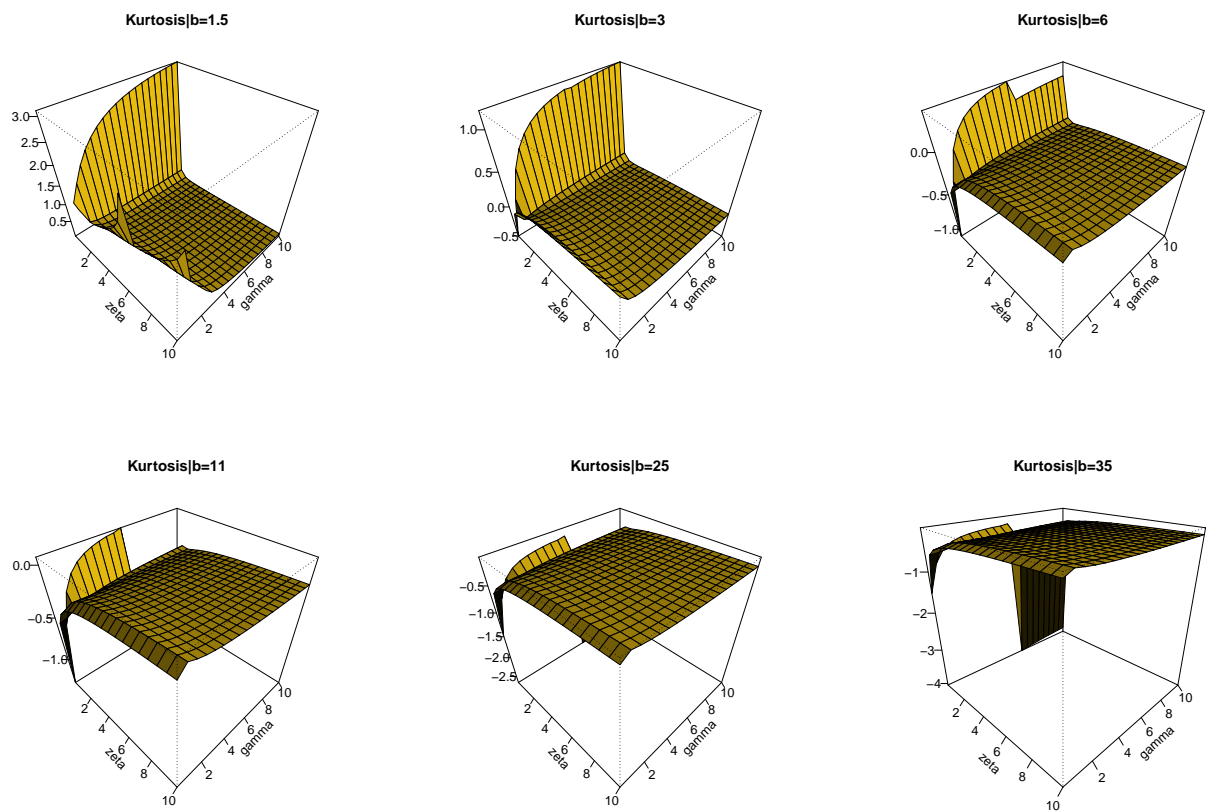

Figure 6. Three dimensional kurtosis plots (KRPTII model).

to generate 1000 samples of size $n$ from the KRPTII distribution;

2. Calculate the MLEs for the 1000 samples, say

$$
\left.\left(\widehat{\zeta}_{i}, \widehat{\gamma}_{i}, \widehat{b}_{i}\right)\right|_{(i=1,2, \ldots, 1000)},
$$

3. Calculate the SEs of the MLEs for the 1000 samples, say

$$
\left.\left(S_{\widehat{\zeta_{i}}}, S_{\widehat{\gamma_{i}}}, S_{\widehat{b_{i}}}\right)\right|_{(i=1,2, \ldots, 1000)} .
$$

4. Calculate the biases $\left(\mathrm{B}_{\hbar}\right)$ and mean squared errors (MSEs) given for $\hbar=\zeta, \beta, b$. We repeated these steps for $n=50,60, \ldots, 500$ with $\zeta=1,2, \ldots, 100, \gamma=1,2, \ldots, 100, b=1,2, \ldots, 100$ so computing biases, mean squared errors $\left(\operatorname{MSE}_{\hbar}(n)\right)$ for $a, b, \zeta$ and $n=50,60, \ldots, 500$ where

$$
\begin{gathered}
\mathrm{B}_{\zeta}=\frac{1}{1000} \sum_{i=1}^{1000}\left(\widehat{\zeta}_{i}-\zeta\right), \mathrm{B}_{\beta}=\frac{1}{1000} \sum_{i=1}^{1000}\left(\widehat{\gamma}_{i}-\gamma\right), \mathrm{B}_{b}=\frac{1}{1000} \sum_{i=1}^{1000}\left(\widehat{b}_{i}-b\right) . \\
\mathrm{MSE}_{\zeta}=\frac{1}{1000} \sum_{i=1}^{1000}\left(\widehat{\zeta}_{i}-\zeta\right)^{2}, \mathrm{MSE}_{\beta}=\frac{1}{1000} \sum_{i=1}^{1000}\left(\widehat{\gamma}_{i}-\gamma\right)^{2}, \mathrm{MSE}_{b}=\frac{1}{1000} \sum_{i=1}^{1000}\left(\widehat{b}_{i}-b\right)^{2} .
\end{gathered}
$$

Figure 7 (left panels) shows how the biases vary with respect to $n$. Figure 7 (right panels) shows how the MSEs vary with respect to $n$. From Figure 7 (left panels), the biases for each parameter decrease to zero as $n \rightarrow \infty$. From Figure 7 (right panels), the MSEs decrease to zero as $n \rightarrow \infty$. Based on this assessment, the maximum likelihood method performs well and can be used in estimating the model parameters. 

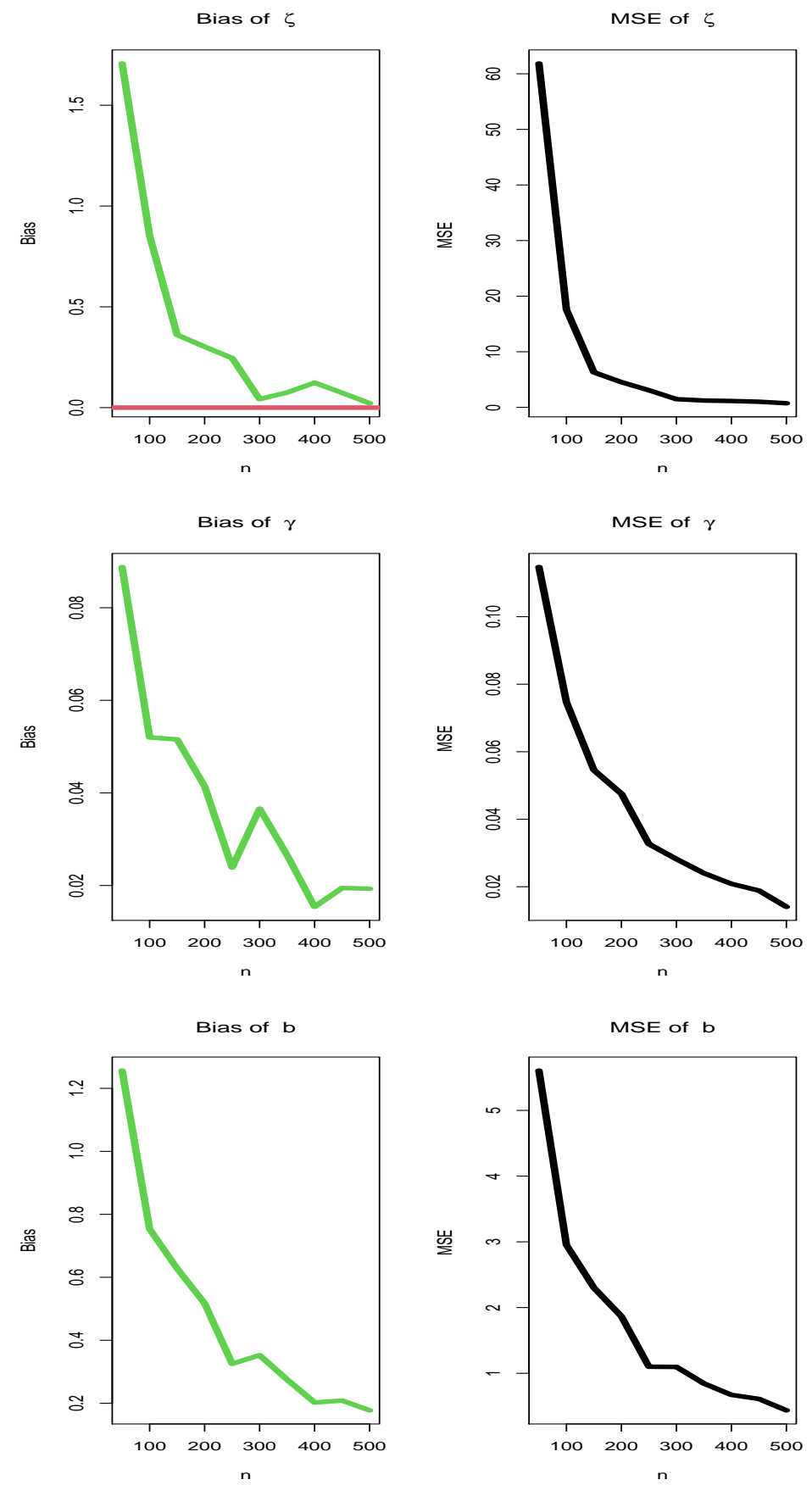

Figure 7. Bias (left panel) and MSE (right panel).

\section{Applications and comparing models}

In this section, we provide two real life applications to two real data sets to illustrate the importance and flexibility of the KRPTII model. We compare the fit of the KRPTII with some well-known competitive models (see Table 2). 
Other relevant models can be used in the comparison, see Gad et al. [21], Tahir et al. [56] and Yousof et al. [58] for more details.
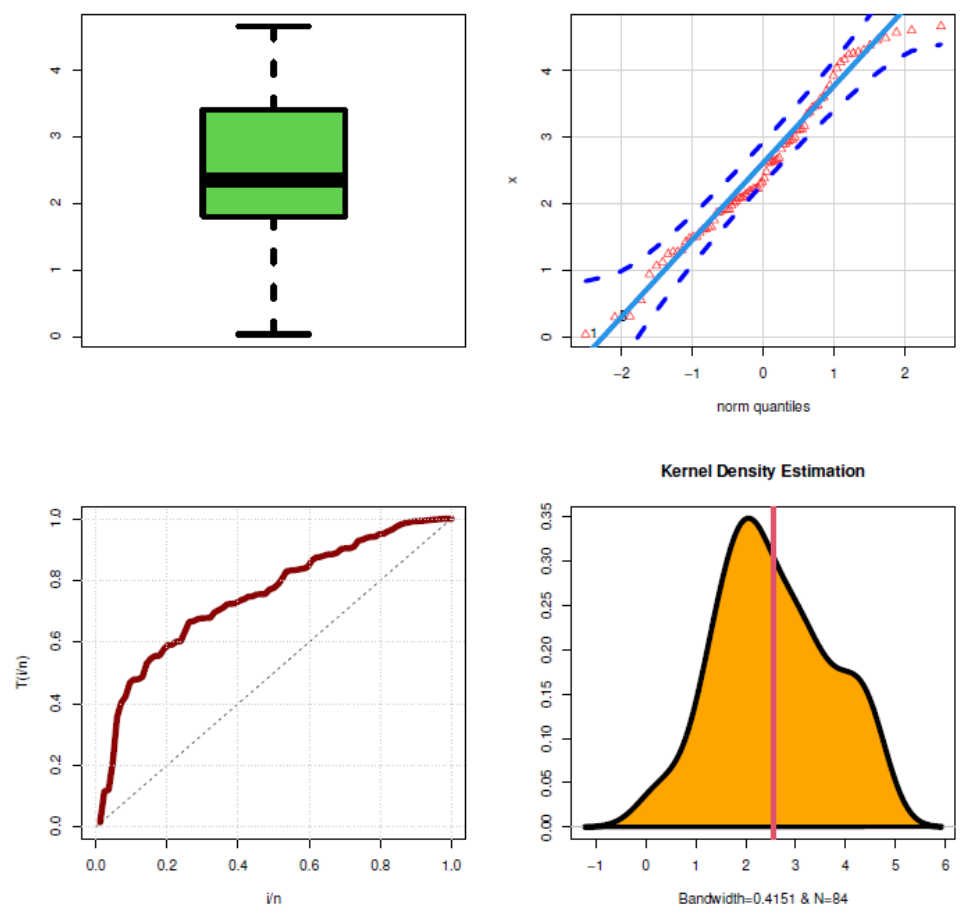

Figure 8. Box plot, Q-Q plot, TTT plot and KDE for failure times data.

Table 2. Competitive models.

\begin{tabular}{cccc}
\hline N. & Model & Abbreviation & Author \\
\hline \hline 1 & Special generalized mixture PTII & SGMPTII & Chesneau and Yousof [11] \\
2 & Odd log-logistic PTII & OLLPTII & Altun et al. [6] \\
3 & Reduced OLLPTII & ROLLPTII & Altun et al. [6] \\
4 & Reduced Burr-Hatke PTII & RBHPTII & Yousof et al. [61] \\
5 & Transmuted Topp-Leone PTII & TTLPTII & Yousof et al. [60] \\
6 & Reduced TTLPTII & RTTLPTII & Yousof et al. [60] \\
7 & Gamma PTII & GamPTII & Cordeiro et al. [14] \\
8 & Kumaraswamy PTII & KumPTII & Lemonte and Cordeiro [37] \\
9 & Beta PTII & BPTII & Lemonte and Cordeiro [37] \\
10 & Exponentiated PTII & ExpPTII & Gupta et al. [25] \\
11 & PTII & PTII & Lomax [38] \\
12 & Proportional reversed hazard rate PTII & PRHRPTII & New \\
\hline \hline
\end{tabular}



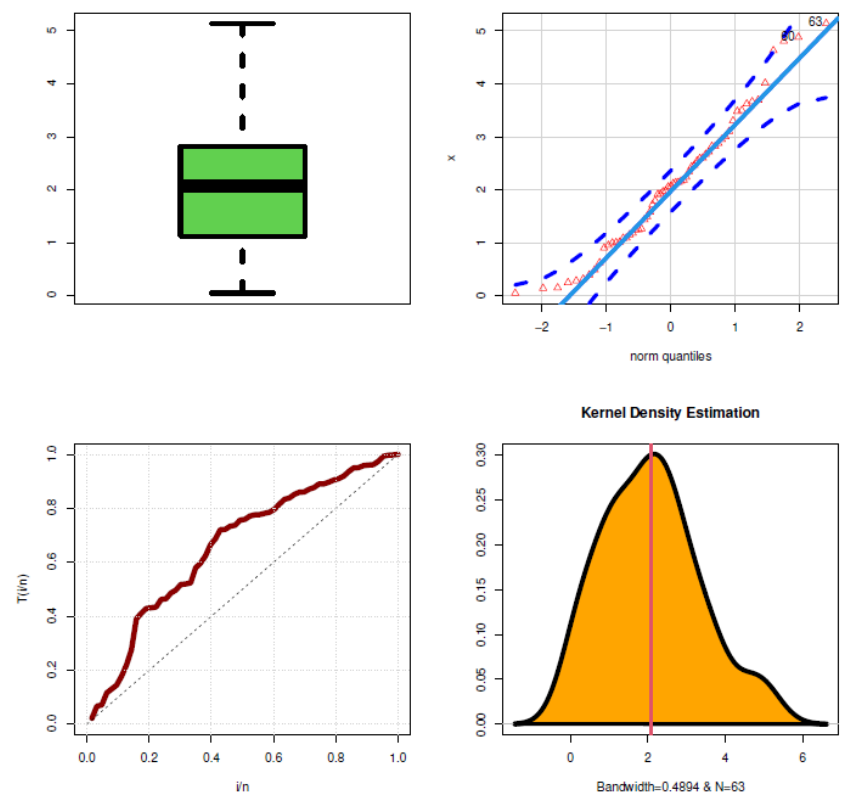

Figure 9. Box plot, Q-Q plot, TTT plot and KDE for service times data.

Data set I (84 Aircraft Windshield): Failure times: The first real data set represents the data on failure times of 84 aircraft windshield given in Murthy et al. [45]. The data are: $0.0400,3.7790,1.248,4.121,1.3030,2.089$, $2.902,4.167,1.4320,2.154,2.9640,4.278,4.449,1.866,2.0850,2.890,2.097,2.934,4.2400,0.943,1.9120$, $2.632,3.5950,1.0700,1.914,2.6460,2.4810,3.467,0.309,1.8990,1.2810,2.038,2.224,3.1170,1.506,3.699$, $2.610,3.4780,0.557,2.1940,3.103,1.9110,1.6190,2.0100,2.688,3.9240,1.480,2.135,2.962,4.2550,1.505$, 2.625,3.5780, 1.615, 2.2230, 3.114, 4.485, 1.652, 2.2290, 1.981, 2.661, 2.190, 3.000, 4.3050, 1.568, 1.1240, 4.376, $2.3850,3.443,0.3010,1.876,2.820,3,4.035,1.281,3.166,4.570,1.652,2.3000,3.344,4.602,1.7570,2.324$, 3.3760, 4.663 .

Data set II (63 Aircraft Windshield): Service times: The second real data set represents the data on service times of 63 aircraft windshield given in Murthy et al. (2004). The data are: 0.046, 0.622, 1.978, 3.0030, 0.9000, $2.053,0.2800,1.794,3.483,1.492,2.600,0.150,3.3040,0.9960,3.1020,0.952,2.065,0.487,2.2400,4.015,1.183$, 2.3410, 2.717, 2.819, 0.3130, 1.915, 2.820, 0.389, 1.9200, 2.878, 1.580, 2.670, 0.248, 1.7190, 1.092, 2.183, 3.695, $1.1520,3.6220,1.085,2.163,3.6650,4.628,1.0030,2.137,3.500,1.0100,2.141,1.9630,2.950,2.117,1.436$, $2.592,0.140,1.2440,2.435,4.806,1.249,2.4640,4.881,1.262,2.5430,5.140$. Many other useful real life data sets can be found in Aryal et al. [9], Yousof et al. [62], Elbiely and Yousof [15], Gad et al. [21], Altun et al. [7], Refaie ([48],[49],[50],[51]), Yadav et al.[55], Mansour et al. [41] and Ibrahim and Yousof [19]. For exploring the outliers, the box plot is plotted in Figures 8(a) and 9(a). Based on Figures 8(a) and 9(a), we note that no outliers were found. For checking the data normality, the Quantile-Quantile (Q-Q) plot is sketched in Figures 8(b) and 9(b). Based on Figures 8(b) and 9(b), we note that the normality is nearly exists. For exploring the shape of the shape of the HRF for the used real data, the total time test (TTT) plot (Aarset [1]) is provided (see Figures 8(c) and 9(c)). Based on Figures 8(c) and 9(c), we note that the HRF is "increasing monotonically" for the two data sets. For exploring the initial shape of real data nonparametrically, kernel density estimation (KDE) is provided in Figures 8(d) and 9(d). Figures 10 and 11 give the estemated Kaplan-Meier survival (EKMS) plot, estemated PDF (EPDF), Probability-Probability (P-P) plot and estemated HRF (EHRF) for data set I and II respectively. The following 

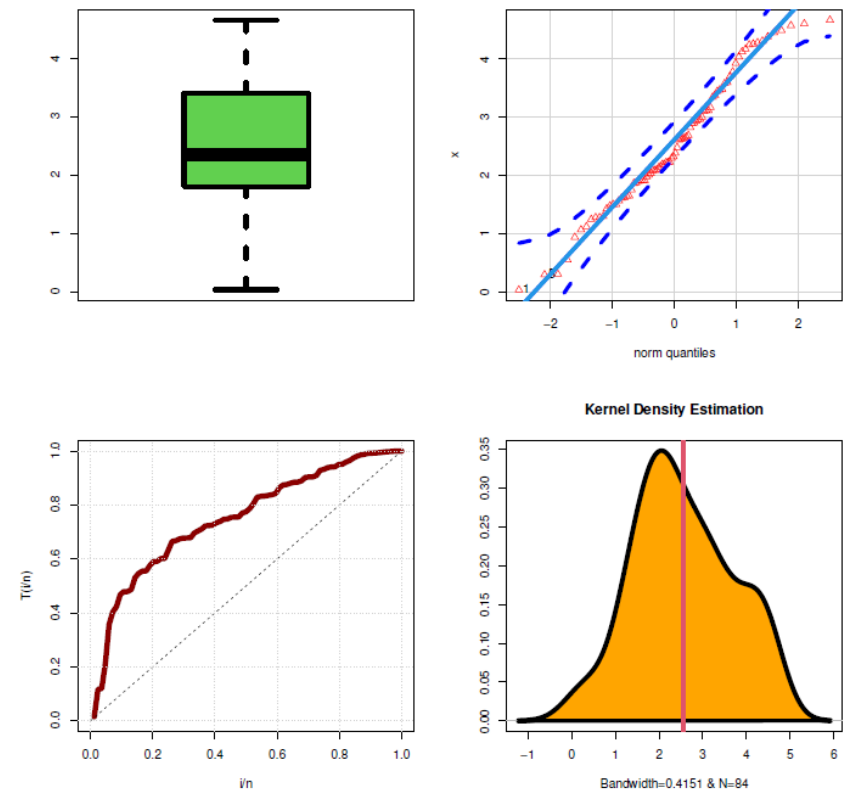

Figure 10. EKMS plot, P-P plot, EPDF plot and EHRF for data set I.

goodness-of-fit statistics are used to compare all competitive models: Akaike Information Criterion $\left(\mathrm{C}_{1}\right)$, Bayesian Information Criterion $\left(\mathrm{C}_{3}\right)$, Consistent Akaike Information Criterion $\left(\mathrm{C}_{2}\right)$, Hannan-Quinn Information Criterion $\left(\mathrm{C}_{4}\right)$, Anderson-Darling $\left(\mathrm{C}_{5}\right)$ and Cramér-von Mises $\left(\mathrm{C}_{6}\right)$. For data set $\mathbf{I}$ : the analysis results of are listed in Tables 3 and 4 . Table 3 gives the MLEs and standard errors (SEs) for failure times data. Table 4 gives the $-\hat{\ell}$ and goodnessof-fits statistics for failure times data. For data set II: the analysis results of are listed in Tables 5 and 6 . Table 5 gives the MLEs and SEs for service times data. Table 6 give the $-\hat{\ell}$ and goodness-of-fits statistics for the service times data. Based on Tables 4 and 6, we note that the KRPTII model gives the lowest values for the $\mathrm{C}_{1}, \mathrm{C}_{2}, \mathrm{C}_{3}, \mathrm{C}_{4}$, $\mathrm{C}_{5}$ and $\mathrm{C}_{6}$ among all fitted models. Hence, it could be chosen as the best model under these criteria.

\section{Conclusions}

Following Cordeiro and de Castro (2011) and Yousof et al. (2016), a new family of distributions called the Kumaraswamy Rayleigh family is defied and studied. Some of its statistical properties including the quantile function, moments, incomplete moments are derived. Many new bivariate type $\mathrm{G}$ families using the copula of Farlie-Gumbel-Morgenstern, modified Farlie-Gumbel-Morgenstern, Clayton copula and Renyi's entropy copula are derived. The method of the maximum likelihood estimation is used. Some special models based on LogLogistic, Exponential, Weibull, Rayleigh, Pareto type-II and Burr X, Lindley distributions are presented and studied. A graphical assessment is performed. Based on this assessment, the maximum likelihood method performs well and can be used in estimating the model parameters. Two real life applications to illustrate the flexibility, potentiality and importance of the new family is proposed. The new family (based on Pareto type-II model) provided results better than the special generalized mixture Pareto type-II, Odd log-logistic Pareto type-II, Reduced Odd log-logistic Pareto type-II, Reduced Burr-Hatke Pareto type-II, Transmuted Topp-Leone Pareto 
type-II, Reduced Transmuted Topp-Leone Pareto type-II, Gamma Pareto type-II, Kumaraswamy Pareto type-II, Beta Pareto type-II, Exponentiated Pareto type-II, standard Pareto type-II and Proportional reversed hazard rate Pareto type-II distributions in modeling survival and service times.

Table 3. MLEs and SEs for failure times data.

\begin{tabular}{|c|c|c|c|c|}
\hline \multirow{2}{*}{ 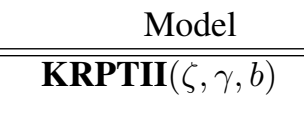 } & \multicolumn{3}{|c|}{ Estimates } & \\
\hline & $\begin{array}{c}0.0824 \\
(0.0091)\end{array}$ & $\begin{array}{l}1.05191 \\
(0.0162)\end{array}$ & $\begin{array}{l}1.12451 \\
(0.0025)\end{array}$ & \\
\hline $\operatorname{KPTII}(\gamma, \beta, b, a)$ & $\begin{array}{c}2.6150 \\
(0.3822)\end{array}$ & $\begin{array}{l}100.276 \\
(120.49)\end{array}$ & $\begin{array}{l}5.27710 \\
(9.8116)\end{array}$ & $\begin{array}{l}78.6774 \\
(186.01)\end{array}$ \\
\hline $\operatorname{TTLPTII}(\gamma, \beta, b, a)$ & $\begin{array}{l}-0.8075 \\
(0.1396)\end{array}$ & $\begin{array}{c}2.47663 \\
(0.542)\end{array}$ & $\begin{array}{l}(15608) \\
(1602.4)\end{array}$ & $\begin{array}{l}(38628) \\
(123.94)\end{array}$ \\
\hline $\operatorname{BPTII}(\gamma, \beta, b, a)$ & $\begin{array}{l}3.60360 \\
(0.6187)\end{array}$ & $\begin{array}{c}33.639 \\
(63.715)\end{array}$ & $\begin{array}{l}4.83070 \\
(9.2382)\end{array}$ & $\begin{array}{l}118.837 \\
(428.93)\end{array}$ \\
\hline $\operatorname{PRHRPTII}(\beta, b, a)$ & $\begin{array}{c}3.7 \times 10^{6} \\
1.01 \times 10^{6}\end{array}$ & $\begin{array}{l}4.7 \times 10^{-1} \\
(0.00001)\end{array}$ & $\begin{array}{l}4.49 \times 10^{6} \\
37.14684\end{array}$ & \\
\hline $\operatorname{SGMPTII}(\gamma, b, a)$ & $\begin{array}{c}-1.04 \times 10^{-1} \\
(0.1223)\end{array}$ & $\begin{array}{l}9.8 \times 10^{6} \\
(4843.3)\end{array}$ & $\begin{array}{c}1.18 \times 10^{7} \\
(501.04)\end{array}$ & \\
\hline $\operatorname{RTTLPTII}(\gamma, \beta, a)$ & $\begin{array}{l}-0.8473 \\
(0.1001)\end{array}$ & $\begin{array}{l}5.52057 \\
(1.1848)\end{array}$ & $\begin{array}{l}1.15678 \\
(0.0959)\end{array}$ & \\
\hline $\operatorname{OLLPTII}(\gamma, b, a)$ & $\begin{array}{c}2.32636 \\
\left(2.1 \times 10^{-1}\right)\end{array}$ & $\begin{array}{l}\left(7.17 \times 10^{5}\right) \\
\left(1.19 \times 10^{4}\right)\end{array}$ & $\begin{array}{c}\left.2.3 \times 10^{6}\right) \\
\left(2.6 \times 10^{1}\right)\end{array}$ & \\
\hline $\operatorname{ExpPTII}(\gamma, b, a)$ & $\begin{array}{l}3.62610 \\
(0.6236)\end{array}$ & $\begin{array}{l}20074.5 \\
(2041.8)\end{array}$ & $\begin{array}{l}26257.7 \\
(99.74)\end{array}$ & \\
\hline $\operatorname{GamPTII}(\gamma, b, a)$ & $\begin{array}{l}3.58760 \\
(0.5133)\end{array}$ & $\begin{array}{c}52001.4 \\
(7955)\end{array}$ & $\begin{array}{l}37029.7 \\
(81.16)\end{array}$ & \\
\hline $\operatorname{ROLLPTII}(\gamma, a)$ & $\begin{array}{l}3.890564 \\
(0.36524)\end{array}$ & $\begin{array}{l}0.57316 \\
(0.0195)\end{array}$ & & \\
\hline $\operatorname{RBHPTII}(b, a)$ & $\begin{array}{l}10801754 \\
(983309)\end{array}$ & $\begin{array}{l}51367189 \\
(232312)\end{array}$ & & \\
\hline $\operatorname{PTII}(b, a)$ & $\begin{array}{l}51425.4 \\
(5933.5) \\
\end{array}$ & $\begin{array}{l}131790 \\
(296.1)\end{array}$ & & \\
\hline
\end{tabular}

Table 4. $-\hat{\ell}$ and goodness-of-fits statistics for failure times data.

\begin{tabular}{cccccccc}
\hline Model & $-\hat{\ell}$ & $\mathrm{C}_{1}$ & $\mathrm{C}_{2}$ & $\mathrm{C}_{3}$ & $\mathrm{C}_{4}$ & $\mathrm{C}_{5}$ & $\mathrm{C}_{6}$ \\
\hline \hline KRPTII & $\mathbf{1 3 0 . 0 6}$ & $\mathbf{2 6 6 . 1 2}$ & $\mathbf{2 6 6 . 4 2}$ & $\mathbf{2 7 3 . 4 1}$ & $\mathbf{2 6 9 . 0 5}$ & $\mathbf{0 . 6 3}$ & $\mathbf{0 . 0 6}$ \\
OLLPTII & 134.42 & 274.85 & 275.15 & 282.14 & 277.78 & 0.94 & 0.10 \\
TTLPTII & 135.57 & 279.14 & 279.65 & 288.86 & 283.05 & 1.13 & 0.13 \\
BPTII & 138.72 & 285.44 & 285.94 & 295.21 & 289.37 & 1.41 & 0.17 \\
GamPTII & 138.40 & 282.81 & 283.11 & 290.14 & 285.76 & 1.37 & 0.16 \\
ExpPTII & 141.40 & 288.80 & 289.10 & 296.13 & 291.75 & 1.74 & 0.22 \\
ROLLPTII & 142.85 & 289.69 & 289.84 & 294.55 & 291.65 & 1.96 & 0.26 \\
SGMPTII & 143.09 & 292.18 & 292.48 & 299.47 & 295.11 & 1.35 & 0.16 \\
RTTLPTII & 153.98 & 313.96 & 314.26 & 321.25 & 316.89 & 3.75 & 0.56 \\
PRHRPTII & 162.88 & 331.75 & 332.05 & 339.05 & 334.69 & 1.37 & 0.16 \\
PTII & 164.99 & 333.98 & 334.12 & 338.86 & 335.94 & 1.39 & 0.17 \\
RBHPTII & 168.60 & 341.21 & 341.36 & 346.07 & 343.16 & 1.67 & 0.21 \\
\hline \hline
\end{tabular}


As a potential future work, we can use and apply many new beneficial goodness-of-fit (GOF) tests for right censored distributional validation such as the Nikulin-Rao-Robson goodness-of-fit test, Bagdonavicius-Nikulin

Table 5. MLEs and SEs for service times data.

\begin{tabular}{|c|c|c|c|c|}
\hline Model & & Estimates & & \\
\hline$\overline{\text { KRPTII }(\zeta, \gamma, b)}$ & $\begin{array}{l}0.12614 \\
(0.0161)\end{array}$ & $\begin{array}{l}0.43080 \\
(0.0065)\end{array}$ & $\begin{array}{l}1.0561 \\
(0.006)\end{array}$ & \\
\hline $\operatorname{BPTII}(\gamma, \beta, b, a)$ & $\begin{array}{c}1.9218 \\
(0.3184)\end{array}$ & $\begin{array}{l}31.2594 \\
(316.84)\end{array}$ & $\begin{array}{l}4.9684 \\
(50.53)\end{array}$ & $\begin{array}{l}169.57 \\
(339.2)\end{array}$ \\
\hline $\operatorname{KPTII}(\gamma, \beta, b, a)$ & $\begin{array}{c}1.6691 \\
(0.2570)\end{array}$ & $\begin{array}{l}60.5673 \\
(86.013)\end{array}$ & $\begin{array}{l}2.5649 \\
(4.759)\end{array}$ & $\begin{array}{l}65.064 \\
(177.6)\end{array}$ \\
\hline $\operatorname{TTLPTII}(\gamma, \beta, b, a)$ & $\begin{array}{c}(-0.607) \\
(0.2137)\end{array}$ & $\begin{array}{l}1.78578 \\
(0.4152)\end{array}$ & $\begin{array}{l}2123.4 \\
(163.9)\end{array}$ & $\begin{array}{l}4822.8 \\
(200.0)\end{array}$ \\
\hline $\operatorname{RTTLPTII}(\gamma, \beta, a)$ & $\begin{array}{l}-0.6715 \\
(0.18746)\end{array}$ & $\begin{array}{l}2.74496 \\
(0.6696)\end{array}$ & $\begin{array}{l}1.0124 \\
(0.114)\end{array}$ & \\
\hline $\operatorname{PRHRPTII}(\beta, b, a)$ & $\begin{array}{l}1.59 \times 10^{6} \\
2.01 \times 10^{3}\end{array}$ & $\begin{array}{c}3.9 \times 10^{-1} \\
0.0004 \times 10^{-1}\end{array}$ & $\begin{array}{l}1.30 \times 10^{6} \\
0.95 \times 10^{6}\end{array}$ & \\
\hline $\operatorname{SGMPTII}(\gamma, b, a)$ & $\begin{array}{l}-1.04 \times 10^{-1} \\
\left(4.1 \times 10^{-10}\right)\end{array}$ & $\begin{array}{c}6.45 \times 10^{6} \\
\left(3.21 \times 10^{6}\right)\end{array}$ & $\begin{array}{c}6.33 \times 10^{6} \\
(3.8573)\end{array}$ & \\
\hline $\operatorname{GamPTII}(\gamma, b, a)$ & $\begin{array}{l}1.9073 \\
(0.321)\end{array}$ & $\begin{array}{c}35842.433 \\
(6945.07)\end{array}$ & $\begin{array}{l}39197.6 \\
(151.65)\end{array}$ & \\
\hline $\operatorname{OLLPTII}(\gamma, b, a)$ & $\begin{array}{c}1.66419 \\
\left(1.79 \times 10^{-1}\right)\end{array}$ & $\begin{array}{l}6.340 \times 10^{5} \\
\left(1.68 \times 10^{4}\right)\end{array}$ & $\begin{array}{l}2.01 \times 10^{6} \\
7.22 \times 10^{6}\end{array}$ & \\
\hline $\operatorname{ExpPTII}(\gamma, b, a)$ & $\begin{array}{l}1.9145 \\
(0.348)\end{array}$ & $\begin{array}{c}22971.15 \\
(3209.5)\end{array}$ & $\begin{array}{c}32882 \\
(162.2)\end{array}$ & \\
\hline $\operatorname{RBHPTII}(b, a)$ & $\begin{array}{c}14055522 \\
(422.01)\end{array}$ & $\begin{array}{c}53203423 \\
(28.523)\end{array}$ & & \\
\hline $\operatorname{ROLLPTII}(\gamma, a)$ & $\begin{array}{l}2.37233 \\
(0.2683)\end{array}$ & $\begin{array}{l}0.69109 \\
(0.0449)\end{array}$ & & \\
\hline $\operatorname{PTII}(b, a)$ & $\begin{array}{l}992700 \\
(11864)\end{array}$ & $\begin{array}{c}207019 \\
(301.24)\end{array}$ & & \\
\hline
\end{tabular}

Table 6. $-\hat{\ell}$ and goodness-of-fits statistics for the service times data.

\begin{tabular}{cccccccc}
\hline Model & $-\hat{\ell}$ & $\mathrm{C}_{1}$ & $\mathrm{C}_{2}$ & $\mathrm{C}_{3}$ & $\mathrm{C}_{4}$ & $\mathrm{C}_{5}$ & $\mathrm{C}_{6}$ \\
\hline \hline KRPTII & $\mathbf{9 8 . 0 7 6}$ & $\mathbf{2 0 2 . 1 5}$ & $\mathbf{2 0 2 . 5 6}$ & $\mathbf{2 0 8 . 5 8}$ & $\mathbf{2 0 4 . 6 8}$ & $\mathbf{0 . 2 2}$ & $\mathbf{0 . 0 3}$ \\
KPTII & 100.87 & 209.74 & 210.43 & 218.31 & 213.11 & 0.74 & 0.12 \\
TTLPTII & 102.45 & 212.90 & 213.59 & 221.47 & 216.27 & 0.94 & 0.16 \\
GamPTII & 102.83 & 211.67 & 212.07 & 218.10 & 214.20 & 1.11 & 0.18 \\
SGMPTII & 102.89 & 211.79 & 212.20 & 218.22 & 214.32 & 1.11 & 0.18 \\
BPTII & 102.96 & 213.92 & 214.61 & 222.50 & 217.29 & 1.13 & 0.19 \\
ExpPTII & 103.55 & 213.10 & 213.51 & 219.53 & 215.63 & 1.23 & 0.20 \\
OLLPTII & 104.90 & 215.81 & 216.22 & 222.24 & 218.34 & 0.94 & 0.16 \\
PRHRPTII & 109.30 & 224.60 & 225.00 & 231.03 & 227.13 & 1.13 & 0.19 \\
PTII & 109.30 & 222.60 & 222.80 & 226.88 & 224.28 & 1.13 & 0.19 \\
ROLLPTII & 110.73 & 225.46 & 225.66 & 229.74 & 227.14 & 2.35 & 0.39 \\
RTTLPTII & 112.19 & 230.37 & 230.78 & 236.80 & 232.90 & 2.69 & 0.45 \\
RBHPTII & 112.60 & 229.20 & 229.40 & 233.49 & 230.89 & 1.40 & 0.23 \\
\hline \hline
\end{tabular}



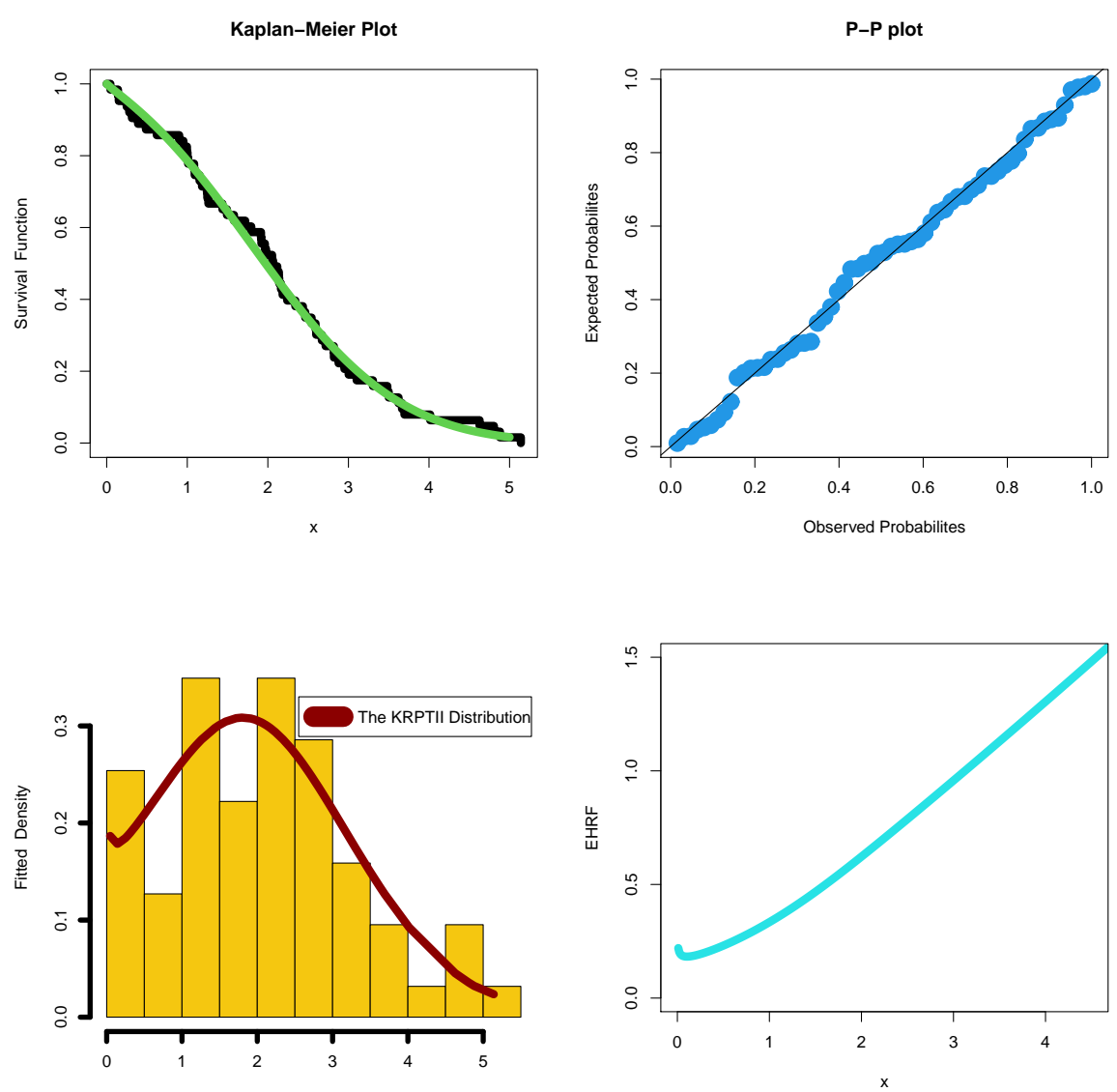

Figure 11. EKMS plot, P-P plot, EPDF plot and EHRF for data set II.

goodness-of-fit test, modified Nikulin-Rao-Robson goodness-of-fit test and modified Bagdonavinius-Nikulin goodness-of-fit test to the new family as recently performed by Ibrahim et al. [18], Abouelmagd et al. [3], Goual et al. ([23], [24]), Mansour et al. ([39], [40]), Yadav et al. [54], Salah et al. [53], Ibrahim et al. [20], Yousof et al. [59] and Goual and Yousof [22], among others. Characterization theorems could be applied for the new Kumaraswamy Rayleigh family (see Hamedani et al. [29], Hamedani et al. [30] and Hamedani et al. [31]). Following Aboraya et al. [2] and Ibrahim et al. [17], we can also convert the Kumaraswamy Rayleigh family to a new discrete G family.

\section{REFERENCES}

1. Aarset, M. V. (1987). How to identify a bathtub hazard rate. IEEE Transactions on Reliability, 36(1), 106-108.

2. Aboraya, M., M. Yousof, H. M., Hamedani, G. G. and Ibrahim, M. (2020). A new family of discrete distributions with nathematical properties, characterizations, Bayesian and non-Bayesian estimation methods. Mathematics, 8, 1648.

3. Abouelmagd, T. H. M., Hamed, M. S., Hamedani, G. G., Ali, M. M., Goual, H., Korkmaz, M. C. and Yousof, H. M. (2019). The zero truncated Poisson Burr X family of distributions with properties, characterizations, applications, and validation test. Journal of Nonlinear Sciences and Applications, 12(5), 314-336.

4. Alizadeh, M., Jamal, F., Yousof, H. M., Khanahmadi, M. and Hamedani, G. G. (2020). Flexible Weibull generated family of distributions: characterizations, mathematical properties and applications. University Politehnica of Bucharest Scientific BulletinSeries A-Applied Mathematics and Physics, 82(1), 145-150.

5. Alizadeh, M., Yousof, H. M., Jahanshahi, S. M. A., Najibi, S. M. and Hamedani, G. G. (2020). The transmuted odd log-logistic-G family of distributions. Journal of Statistics and Management Systems, 23(4), 1-27. 
6. Altun, E., Yousof, H. M. and Hamedani, G. G. (2018a). A new log-location regression model with influence diagnostics and residual analysis. Facta Universitatis, Series: Mathematics and Informatics, 33(3), 417-449.

7. Altun, E., Yousof, H. M., Chakraborty, S. and Handique, L. (2018b). Zografos-Balakrishnan Burr XII distribution: regression modeling and applications. International Journal of Mathematics and Statistics, 19(3), 46-70.

8. Aryal, G. R. and Yousof, H. M. (2017). The exponentiated generalized-G Poisson family of distributions. Stochastics and Quality Control, 32(1), 7-23

9. Aryal, G. R., Ortega, E. M., Hamedani, G. G. and Yousof, H. M. (2017). The Topp Leone Generated Weibull distribution: regression model, characterizations and applications, International Journal of Statistics and Probability, 6, 126-141.

10. Brito, E., Cordeiro, G. M., Yousof, H. M., Alizadeh, M. and Silva, G. O. (2017). The Topp-Leone odd log-logistic family of distributions. Journal of Statistical Computation and Simulation, 87(15), 3040-3058.

11. Chesneau, C. and Yousof, H. M. (2021). On a special generalized mixture class of probabilitic models. Journal of Nonlinear Modeling and Analysis, orthcoming.

12. Cordeiro, G. M., Yousof, H. M., Ramires, T. G. and Ortega, E. M. M. (2018). The Burr XII system of densities: properties, regression model and applications. Journal of Statistical Computation and Simulation, 88(3), 432-456.

13. Cordeiro, G.M. and de Castro, M. (2011). A new family of generalized distributions. J. Stat. Comput. Simul., 81, 883-893.

14. Cordeiro, G. M., Ortega, E. M. and Popovic, B. V. (2015). The gamma-Lomax distribution. Journal of Statistical computation and Simulation, 85(2), 305-319.

15. Elbiely, M. M. and Yousof, H. M. (2018). A New Extension of the Lomax Distribution and its Applications, Journal of Statistics and Applications, 2(1), 18-34.

16. El-Morshedy, M., Alshammari, F. S., Hamed, Y. S., Eliwa, M. S., Yousof, H. M. (2021). A New Family of Continuous Probability Distributions. Entropy, 23, 194

17. Ibrahim, M., Ali, M. M. and Yousof, H. M. (2021). The discrete analogue of the Weibull G family: properties, different applications, Bayesian and non-Bayesian estimation methods. Annals of Data Science, forthcoming.

18. Ibrahim, M., Altun, E., Goual, H., and Yousof, H. M. (2020). Modified goodness-of-fit type test for censored validation under a new Burr type XII distribution with different methods of estimation and regression modeling. Eurasian Bulletin of Mathematics, 3(3), $162-182$.

19. Ibrahim, M. and Yousof, H. M. (2020). A new generalized Lomax model: statistical properties and applications, Journal of Data Science, 18(1), $190-217$.

20. Ibrahim, M., Yadav, A. S., Yousof, H. M., Goual, H. and Hamedani, G. G. (2019). A new extension of Lindley distribution: modified validation test, characterizations and different methods of estimation. Communications for Statistical Applications and Methods, 26(5), 473-495.

21. Gad, A. M., Hamedani, G. G., Salehabadi, S. M. and Yousof, H. M. (2019). The Burr XII-Burr XII distribution: mathematical properties and characterizations. Pakistan Journal of Statistics, 35(3), 229-248.

22. Goual, H. and Yousof, H. M. (2020). Validation of Burr XII inverse Rayleigh model via a modified chi-squared goodness-of-fit test. Journal of Applied Statistics, 47(3), 393-423.

23. Goual, H., Yousof, H. M. and Ali, M. M. (2019). Validation of the odd Lindley exponentiated exponential by a modified goodness of fit test with applications to censored and complete data. Pakistan Journal of Statistics and Operation Research, 15(3), 745-771.

24. Goual, H., Yousof, H. M. and Ali, M. M. (2020). Lomax inverse Weibull model: properties, applications, and a modified Chi-squared goodness-of-fit test for validation. Journal of Nonlinear Sciences \& Applications (JNSA), 13(6), 330-353.

25. Gupta, R. C., Gupta, P. L. and Gupta, R. D. (1998). Modeling failure time data by Lehman alternatives. Communications in StatisticsTheory and methods, 27(4), 887-904.

26. Ghosh, I. and Ray. S. (2016). Some alternative bivariate Kumaraswamy type distributions via copula with application in risk management. Journal of Statistical Theory and Practice 10, 693-706.

27. Gumbel, E. J. (1961). Bivariate logistic distributions. Journal of the American Statistical Association, 56(294), 335-349.

28. Gumbel, E. J. (1960) Bivariate exponential distributions. Journ. Amer. Statist. Assoc., 55, 698-707.

29. Hamedani, G. G., Altun, E., Korkmaz, M. C., Yousof, H. M. and Butt, N. S. (2018). A new extended G family of continuous distributions with mathematical properties, characterizations and regression modeling. Pakistan Journal of Statistics and Operation Research, 737-758.

30. Hamedani, G. G., Rasekhi, M., Najibi, S., Yousof, H. M. and Alizadeh, M. (2019). Type II general exponential class of distributions Pakistan Journal of Statistics and Operation Research, 15(2), 503-523.

31. Hamedani, G. G., Yousof, H. M., Rasekhi, M., Alizadeh, M. and Najibi, S. M., (2018). Type I general exponential class of distributions. Pakistan Journal of Statistics and Operation Research, 14(1), 39-55.

32. Karamikabir, H., Afshari, M., Yousof, H. M., Alizadeh, M., \& Hamedani, G. (2020). The Weibull Topp-Leone Generated Family of Distributions: Statistical Properties and Applications. Journal of The Iranian Statistical Society, 19(1), 121-161.

33. Korkmaz, M. C., Alizadeh, M., Yousof, H. M. and Butt, N. S. (2018a). The generalized odd Weibull generated family of distributions: statistical properties and applications. Pakistan Journal of Statistics and Operation Research, 541-556.

34. Korkmaz, M. 627., Altun, E., Yousof, H. M. and Hamedani, G. G. (2020). The Hjorth's IDB Generator of Distributions: Properties, Characterizations, Regression Modeling and Applications. Journal of Statistical Theory and Applications, 19(1), 59-74.

35. Korkmaz, M. C., Yousof, H. M. and Hamedani, G. G. (2018b). The exponential Lindley odd log-logistic-G family: properties, characterizations and applications. Journal of Statistical Theory and Applications, 17(3), 554-571.

36. Korkmaz, M. C., Yousof, H. M., Hamedani, G. G. and Ali, M. M. (2018c). The Marshall-Olkin generalized G Poisson family of distributions. Pak. J. Statist, 34(3), 251-267.

37. Lemonte, A. J. and Cordeiro, G. M. (2013). An extended Lomax distribution. Statistics, 47(4), 800-816.

38. Lomax, K.S. (1954). Business failures: Another example of the analysis of failure data, Journal of the American Statistical Association, 49, 847-852.

39. Mansour, M. M., Ibrahim, M., Aidi, K., Shafique Butt, N., Ali, M. M., Yousof, H. M. and Hamed, M. S. (2020a). A New Log-Logistic Lifetime Model with Mathematical Properties, Copula, Modified Goodness-of-Fit Test for Validation and Real Data Modeling. 
Mathematics, 8(9), 1508.

40. Mansour, M., Rasekhi, M., Ibrahim, M., Aidi, K., Yousof, H. M. and Elrazik, E. A. (2020b). A New Parametric Life Distribution with Modified Bagdonavičius-Nikulin Goodness-of-Fit Test for Censored Validation, Properties, Applications, and Different Estimation Methods. Entropy, 22(5), 592.

41. Mansour, M., Yousof, H. M., Shehata, W. A. M. and Ibrahim, M. (2020c). A new two parameter Burr XII distribution: properties,copula, different estimation methods and modeling acute bone cancer data, Journal of Nonlinear Science and Applications, $13,223-238$.

42. Marshall, A. W. and Olkin, I. (1997). A new method for adding a parameter to a family of distributions with application to the exponential and Weibull families. Biometrika, 84(3), 641-652.

43. Merovci, F., Alizadeh, M., Yousof, H. M. and Hamedani, G. G. (2017). The exponentiated transmuted-G family of distributions: theory and applications. Communications in Statistics-Theory and Methods, 46(21), 10800-10822.

44. Merovci, F., Yousof, H. M. and Hamedani, G. G. (2020). The Poisson Topp Leone Generator of Distributions for Lifetime Data: Theory, Characterizations and Applications. Pakistan Journal of Statistics and Operation Research, 16(2), 343-355.

45. Murthy, D.N.P. Xie, M. and Jiang, R. (2004). Weibull Models, Wiley.

46. Nascimento, A. D., Silva, K. F., Cordeiro, G. M., Alizadeh, M., Yousof, H. M., \& Hamedani, G. G. (2019). The odd NadarajahHaghighi family of distributions: properties and applications. Studia Scientiarum Mathematicarum Hungarica, 56(2), $185-210$.

47. Pougaza, D. B. and Djafari, M. A. (2011). Maximum entropies copulas. Proceedings of the 30th international workshop on Bayesian inference and maximum Entropy methods in Science and Engineering, 329-336.

48. Refaie, M. K. A. (2018a). A new version of the zero truncated Poisson exponential distribution for modeling relief and survival times. Journal of Statistics and Applications, 1(2), 89-107.

49. Refaie, M. K. A. (2018b). Burr X exponentiated exponential distribution. Journal of Statistics and Applications, 1(2), 71-88.

50. Refaie, M. K. A. (2018c). Extended Poisson-exponentiated Weibull distribution: theoretical and computational aspects. pak. j. statist, 34(6), 513-530.

51. Refaie, M. K. A. (2019). A new two-parameter exponentiated Weibull model with properties and applications to failure and survival times. International Journal of Mathematical Archive, 10(2), 1-13.

52. Rodriguez-Lallena, J. A. and Ubeda-Flores, M. (2004). A new class of bivariate copulas. Statistics and Probability Letters, 66, $315-25$.

53. Salah, M. M., El-Morshedy, M., Eliwa, M. S. and Yousof, H. M. (2020). Expanded Fréchet Model: Mathematical Properties, Copula, Different Estimation Methods, Applications and Validation Testing. Mathematics, 8(11), 1949.

54. Yadav, A. S., Altun, E., \& Yousof, H. M. (2019). Burr-Hatke Exponential Distribution: A Decreasing Failure Rate Model, Statistical Inference and Applications. Annals of Data Science, 1-20.

55. Yadav, A.S., Goual, H., Alotaibi, R.M. Rezk, H., Ali, M.M. and Yousof, H.M. (2020). Validation of the Topp-Leone-Lomax model via a modified Nikulin-Rao-Robson goodness-of-fit test with different methods of estimation. Symmetry, 12, 1-26. doi: $10.3390 /$ sym 12010057

56. Tahir, M. H., Cordeiro, G. M., Mansoor, M. and Zubair, M. (2015). The Weibull-Lomax distribution: properties and applications. Hacettepe Journal of Mathematics and Statistics, 44(2), 461-480.

57. Yousof, H. M., Afify, A. Z., Hamedani, G. G. and Aryal, G. (2017). The Burr X generator of distributions for lifetime data. Journal of Statistical Theory and Applications, 16(3), 288-305.

58. Yousof, H. M., Ahsanullah, M. and Khalil, M. G. (2019). A new zero-truncated version of the Poisson Burr XII distribution: characterizations and properties. Journal of Statistical Theory and Applications, 18(1), 1-11.

59. Yousof, H. M., Aidi, K., Hamedani, G. G and Ibrahim, M. (2021). A new parametric lifetime distribution with modified Chi-square type test for right censored validation, characterizations and different estimation methods. Pakistan Journal of Statistics and Operation Research, 17(2), forthcoming.

60. Yousof, H. M., Alizadeh, M., Jahanshahiand, S. M. A., Ramires, T. G., Ghosh, I. and Hamedani, G. G. (2017). The transmuted Topp-Leone $\mathrm{G}$ family of distributions: theory, characterizations and applications. Journal of Data Science, 15(4), 723-740.

61. Yousof, H. M., Altun, E., Ramires, T. G., Alizadeh, M. and Rasekhi, M. (2018). A new family of distributions with properties, regression models and applications, Journal of Statistics and Management Systems, 21, 1, 163-188.

62. Yousof, H. M., Majumder, M., Jahanshahi, S. M. A., Ali, M. M. and Hamedani G. G. (2018). A new Weibull class of distributions: theory, characterizations and applications, Journal of Statistical Research of Iran, 15, 45-83.

63. Zografos, K. and Balakrishnan, N. (2009). On families of beta-and generalized gamma-generated distributions and associated inference. Statistical methodology, 6(4), 344-362. 